\title{
تاثير استقر ارية بعض الانشطة السلعية في العراق على تقدير نماذج البيانات المقطعية للفترة (1988-2000)
}

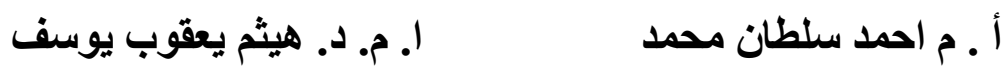 \\ كلية الادارة والاقتصاد/ جامعة ديالى هلى
}

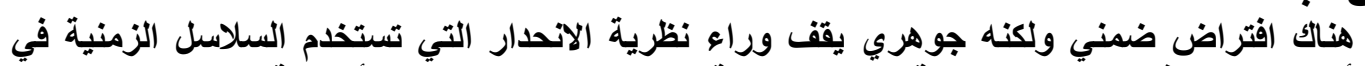

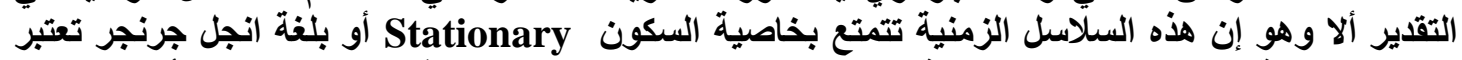

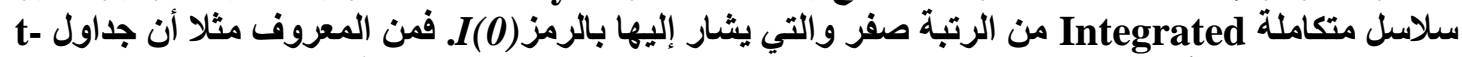
statistic

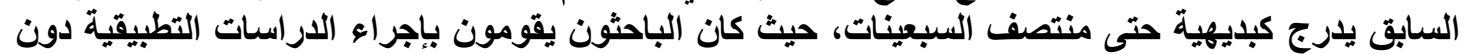

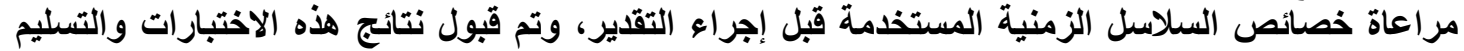

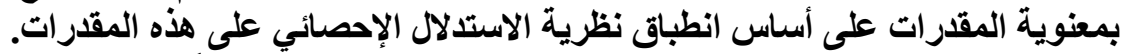

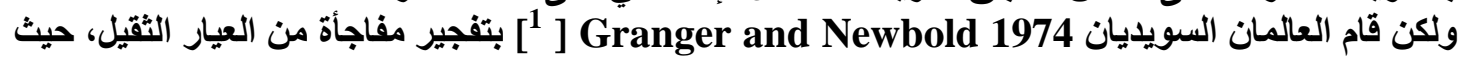

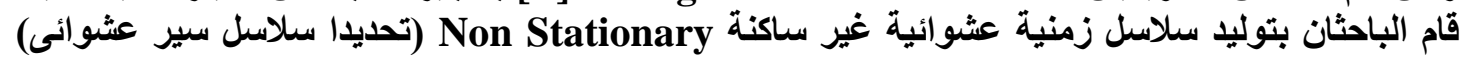

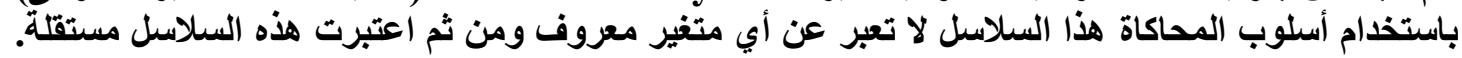

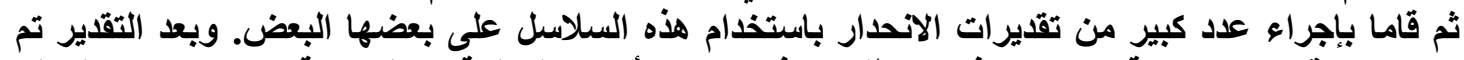

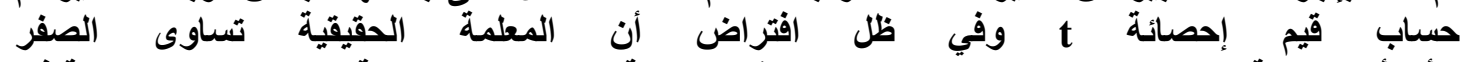

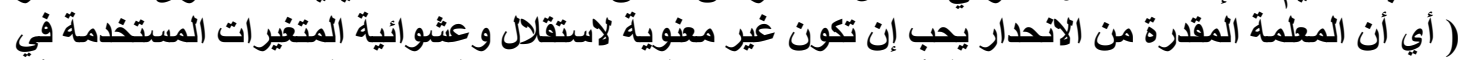

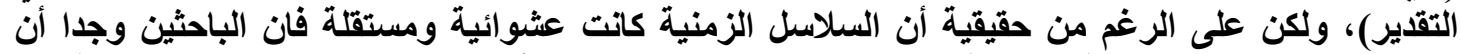

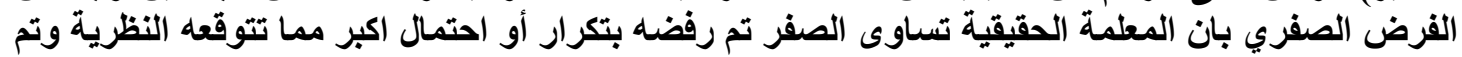

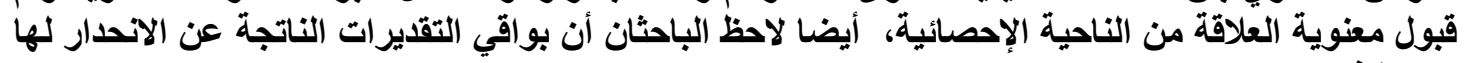

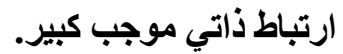

ويذلك توصل الباحث إلى نتيجة هامة وخطيرة مفادها أن المقدرات والاختبارات الإحصائية التي تنتج عن فئن

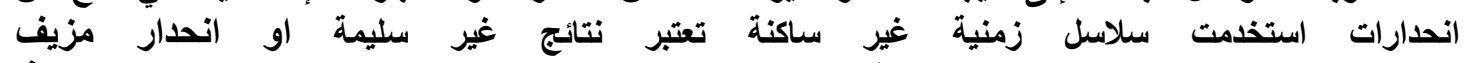

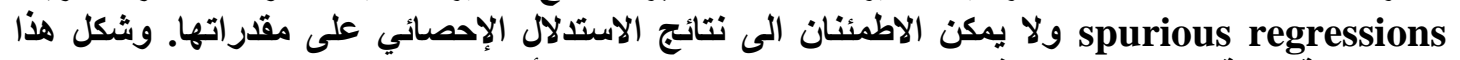

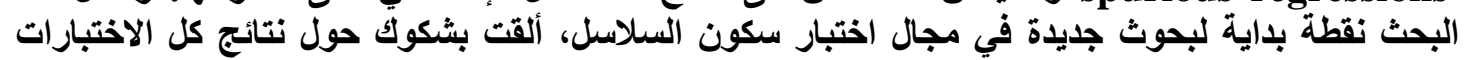

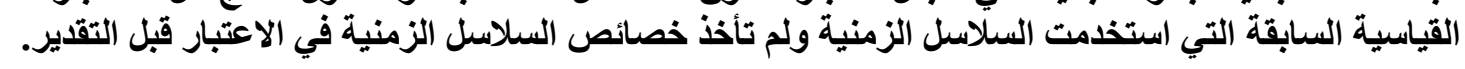

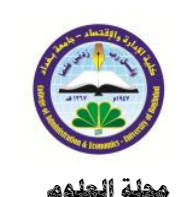

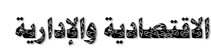

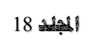

66 ฌा

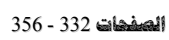

RITCHARD HARRIS, Using COINTEGRATION ANALYSIS IN ECONOMICS MODLELLINMG,

Prentice Hall, LONDON, 1995, pp(23) 


\section{العدد 66}

تاثير استقرارية بعضر الانشطة السلعية في العراق على تقدير نماذج

$$
\text { البيانات المقطعية للفترة (1988-2000) }
$$

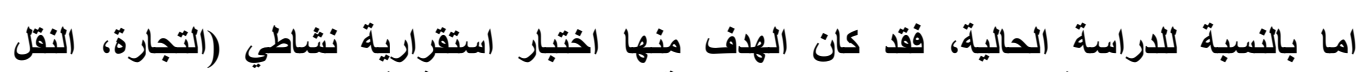

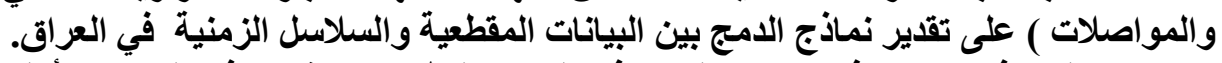

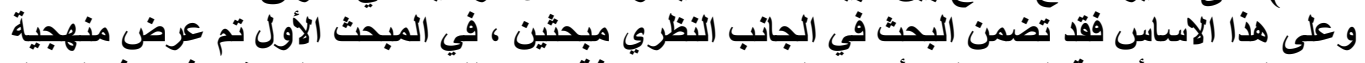

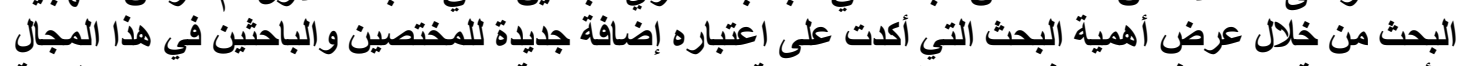

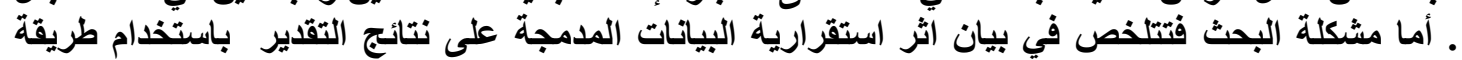

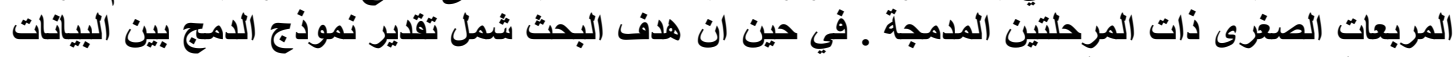

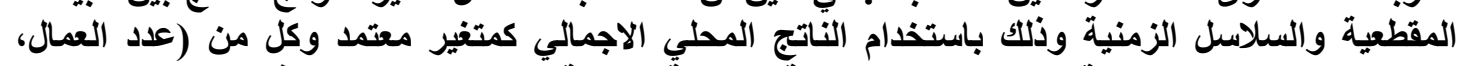

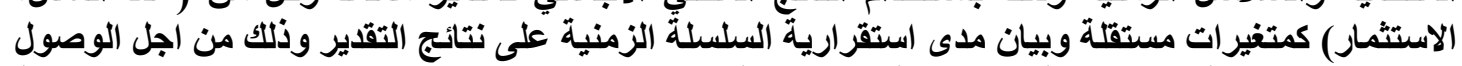

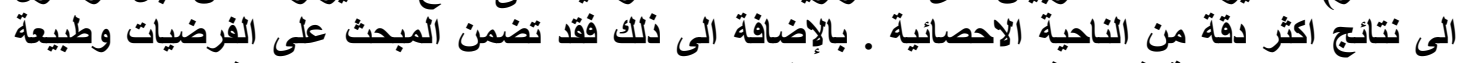

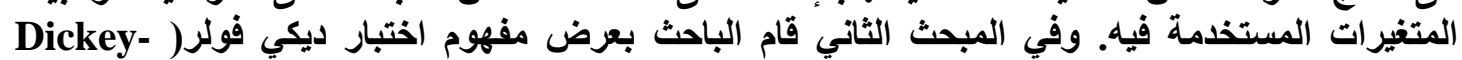
(Fuller

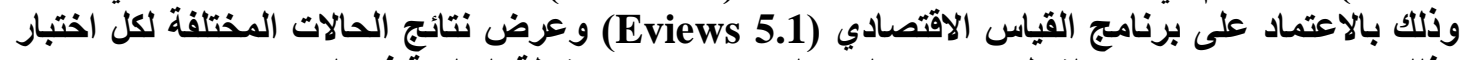

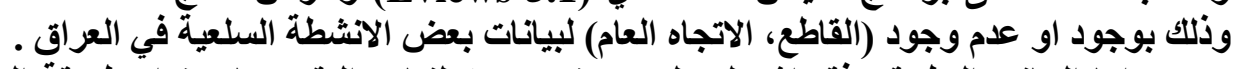

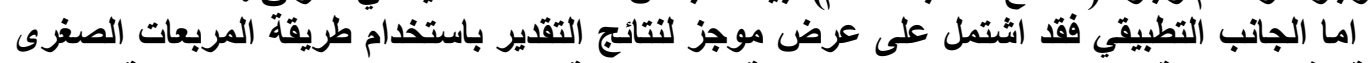

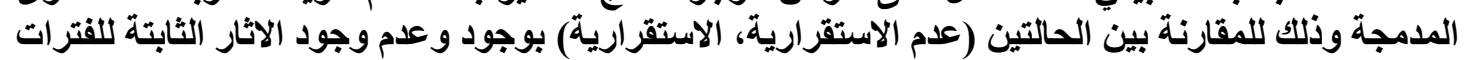
والمجاميع. أخيرا عرض الباحث الاستتتاجات والتوصيات التي توصل لها البحث. 
تاثير استقرارية بـعض الانشطة السلعية في العراق على تقدير نماذج

البيانات المقطعية للفترة (1988-2000)

\section{Stabilizing effect of some commodity activities in Iraq to assess the Panel data data models for the period (1988-2000) \\ Summery}

There is an assumption implicit but fundamental theory behind the decline by the time series used in the estimate, namely that the time series has a sleep feature Stationary or the language of Engle Gernger chains are integrated level zero, which indicated by I (0). It is well known, for example, tables of t-statistic is designed primarily to deal with the results of the regression that uses static strings. This assumption has been previously treated as an axiom the midseventies, where researchers are conducting studies of applied without taking into account the properties of time series used prior to the assessment, was to accept the results of these tests Bmanueh and delivery capabilities based on the applicability of the theory of statistical inference on these capabilities. But the scientists Swedes Granger and Newbold 1974 blew up real surprise when, where researchers generate the time series random static Stationary Non (specifically chains conduct random) using the method of simulation of this series does not reflect any variable is known and then considered these chains separately. And then they make a large number of estimates of the regression using these strings on each other.

After the estimate was calculated values of statistic $t$ and under the assumption that the parameter real equal to zero (ie, the parameter estimates from the regression likes to be insignificant to the independence and random variables used in the estimate), but in spite of the fact that the time series was random and independent, the researchers found that zero hypothesis that the true parameter equal to zero was rejected or the possibility of greater frequency than expected by the theory were accepted moral relationship statistically, the researchers also noted that the residue resulting from the regression estimates by a large positive self-link. The researchers reached this conclusion important and serious that the capacity and statistical tests that result from the regressions used the time series is still considered the results of improper or false decline spurious regressions can not be reassuring to the results of statistical inference on its resources. The form of this research the starting point for new research in the field of sleep testing strings, cast doubt on the results of all previous standard tests used did not take the time series properties of time series into account by the estimate.

As for the current study, the test was intended to stabilize some of the activities in Iraq and the commodity involved (agriculture, manufacturing, construction, electricity and water) to estimate the models of integration between the cross-sectional data and time series. 


\section{6 العدادئ}

$$
\begin{aligned}
& \text { تاثير استقرارية بـعض الانشطة السلعية في العراق على تقدير نماذف } \\
& \text { البيانات المقطعية للفترة (1988-2000) }
\end{aligned}
$$

On this basis, the research contained in the theoretical side Mbgesan, in the first part, the research methodology was presented by showing the importance of research which confirmed the account on the new addition to the specialists and researchers in this field. The research problem can be summarized in a statement after stabilizing the merged data on the results of the assessment method of least squares using the two-stage compact. While the aim of the research included the assessment of model integration between the data crosssectional and time series using the GDP variable is supported and all of (the number of workers, investment) independent variables indicate the extent to stabilize the time series on the results of the assessment in order to reach more accurate results from a statistical standpoint . In addition, ensure the topic on the assumptions and the nature of the variables used in it. In the second part, the researchers introduced the concept of testing Dickey Fuller used in detecting the presence of the root of the unit (Unit root) and applied to the data used in the research, based on a program of economic measurement (Eviews 5.1) and present the results of different cases for each test and the presence or absence (Cutter, the general trend) to the data of some commodity activities in Iraq. The practical side has included a summary of the results of the assessment using the least squares method combined with a comparison between the two cases (non-stability, stability,) in the presence and the absence of fixed effects of periods and groups.

Finally, the researchers offer conclusions and recommendations reached by the research. 


\section{العدد 66}

تاثير استقرارية بعضر الانشطة السلعية في العراق على تقدير نماذج

$$
\text { البيانات المقطعية للفنترة (1988-2000) }
$$

$$
\text { المبحث الاول/ منهجيــة البـحث }
$$

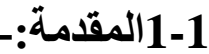

يمثل الناتج المحلي الإجمالي احد أهم المؤشرات الاقتصادية التي تستخلم في التحليل الاقتصادي وكلما

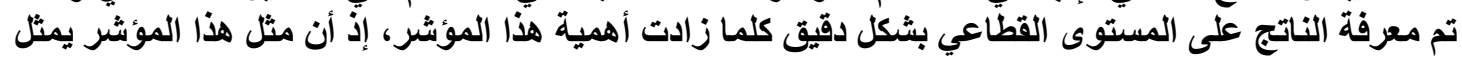

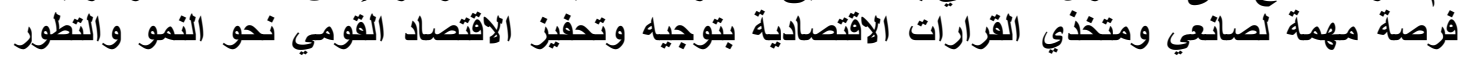

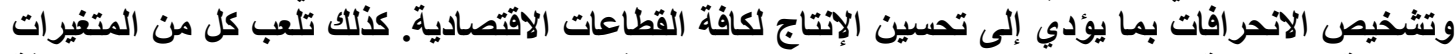

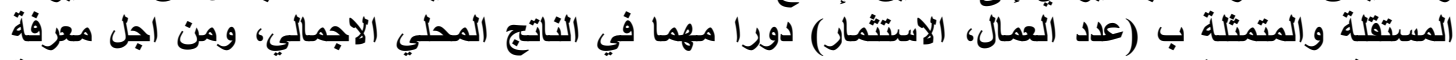

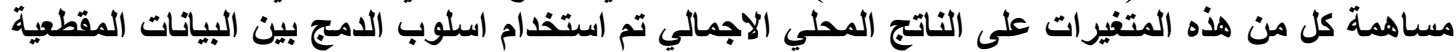

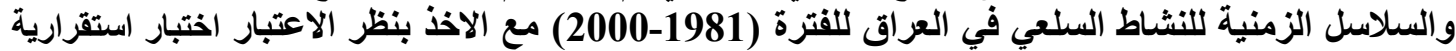

هذه البيانات وحسب الطرق التي يوفُرها برنامج القياس الاقتصادي (Eviews 5.1) 1-2 هدف البحث:-

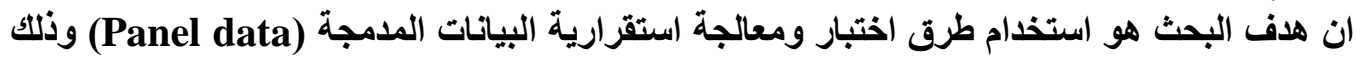

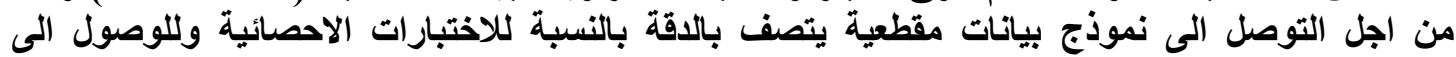

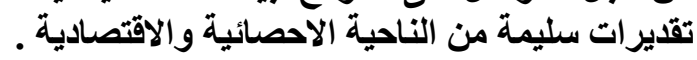

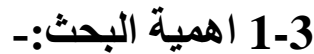

تأتي أهية البحث في إضافة مصدر جديد اللباحثين في مجال استخدام طرق اختبار استقرارية الامج بين

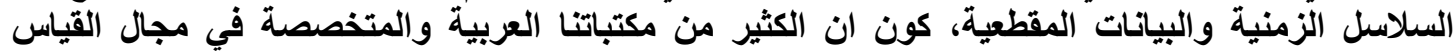

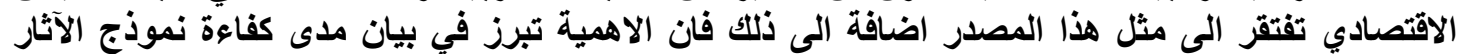

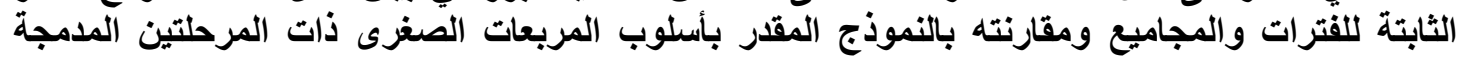

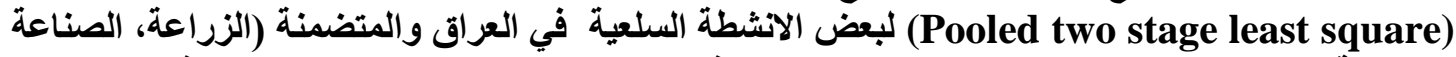

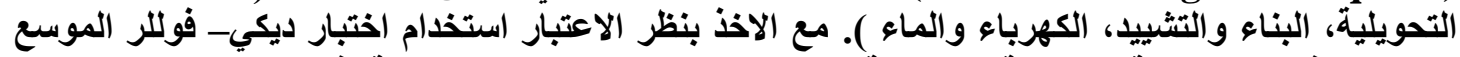
في استقرارية السلسلة المقطعية (ADF) الاستقرارية في على نتائج التقدير. [2] في استخراج النتائج (Eviews 5.1) 1-4 مشكلة البحث :-

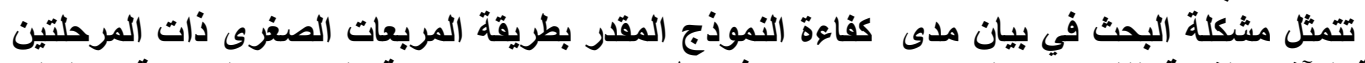

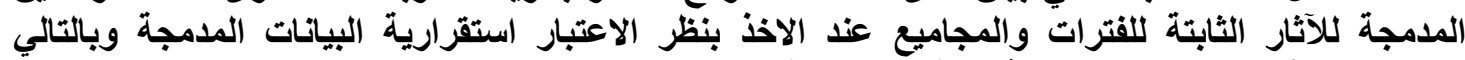

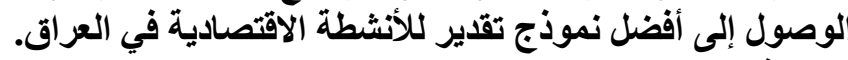

$$
\begin{aligned}
& \text { يتضمن البحث اختبار فرضيات العدم التالية:- } \\
& \text { 1-5 فرضيات البحث:- البهن }
\end{aligned}
$$

H01:- عدم وجود فروق معنوية للنموذج المقدر بوجود قاطع لمستوى السلسلة الزمنية والبيانات المقطعية

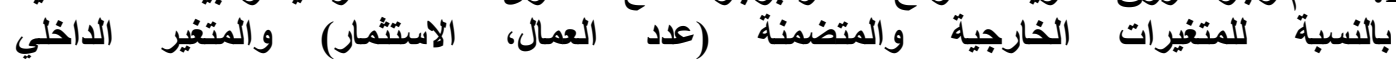

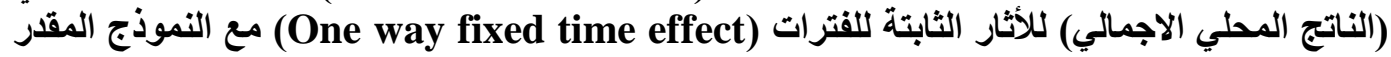

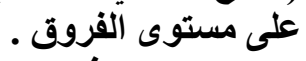
H02:- علم وجود فروق معنوية للنموذج المقدر بوجود قاطع لمستوى السلسلة الزمنية والبيانات المقطعية للأثار الثابتة للمجاميع (One way fixed group effect) مع النموذج المغود المقدر على مستوى الفروق . 


\section{6 العدد 6}

تاثير استنقرارية بـعض الانشطة السلعية في العراق على تقدير نماذج

$$
\text { البيانات المقطعية للفترة (1988-2000) }
$$

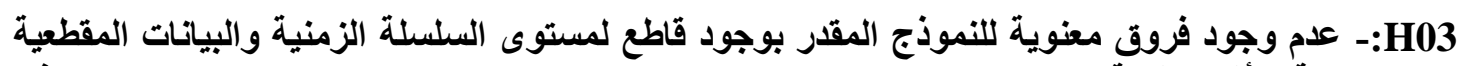
بالنسبة للأثار الثابتة للفترات والمجاميع (Two way fixed time- group effect) مع فئون النموذج

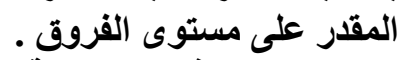
H04:- عدم وجود فروق معنوية للنموذج المقدر بوجود قاطع واتجاه عام لمستوى السلسلة الزمنية والبيانات

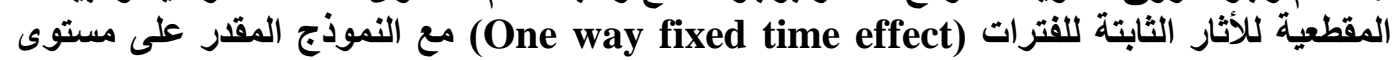

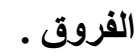
H05:H علدم وجود فروق معنوية للنموذج المقدر بوجود قاطع واتجاه عام لمستوى السلسلة الزمنية والبيانات المقطعية للأثار الثابتة للمجاميع (One way fixed group effect) مع النموذج وانج المقدر على مستوى

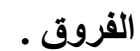
H06:H عدم وجود فروق معنوية للنموذج المقدر بوجود قاطع واتجاه عام لمستوى السلسلة الزمنية والبيانات

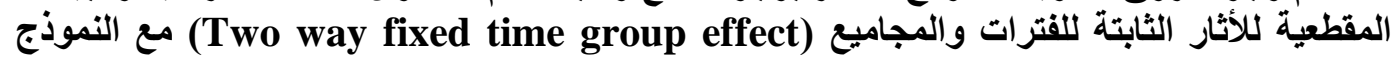

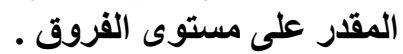

H07:H عدم وجود فروق معنوية للنموذج المقدر عند عدم وجود قاطع واتجاه عام لمستوى السلسلة الزمنية

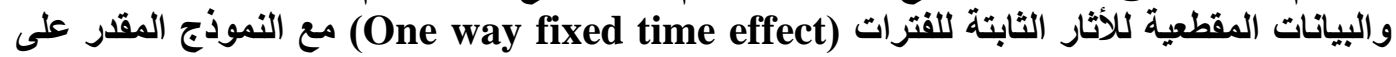

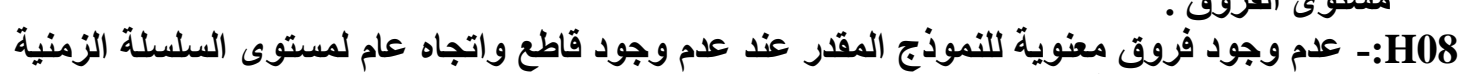

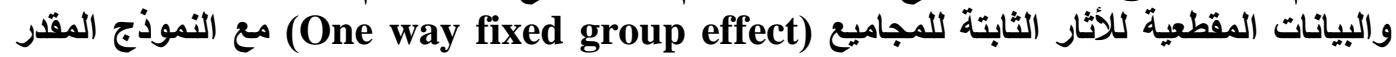
على مستوى الفروق .



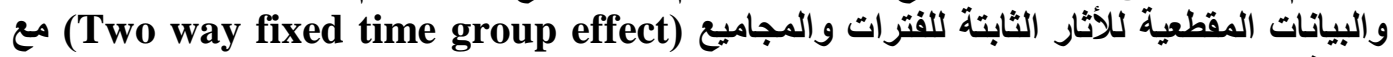

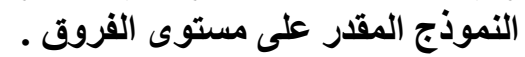
1-6 متغيرات البحث:- المفودئ

تم تطبيق نموذج الدئ الدج بين البيانات المقطعية والسلاسل الزمنية على البيانات الخاصة للأنشطة الاقتصادية في العراق للفترة (1981-2000) وذلك باستخدام المتغيرات التالية :-

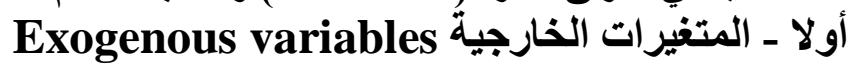
No. of employees عدد المشتخلين: X1 Investment الاستثمار :-: X2 ويعرف بانه تخصيص رأس المالف لإلفال للحصول على وسائل انتاجية جديدة او لتطوير الوسائل الموجودة لغاية زيادة الطاقة الانتاجية ثانيا:- المتفيرات الأخلية Endogenous variables فقد كاتت كما يلي:-

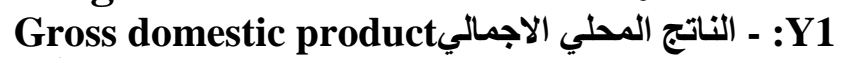

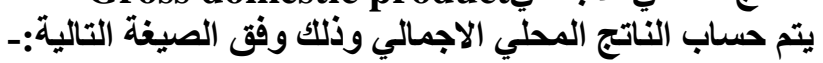
تعويضات المشتفلين + فائض العمليات + تخصيصات استهلاك راس الماتلة المال الثابت + الضرائب الغير المباشرة

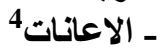
والجدول الآتي يبين البيانات المستخدمة في البحث بالنسبة للمتغيرات الداخلية والخارجية والمستخدمة في التقدير. 
تاثير استقرارية بـعض الانشطة السلعية في العراق على تقدير نماذف

البيانات المقطعية للفترة (1988-2000)

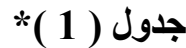

\begin{tabular}{|c|c|c|c|c|c|}
\hline بالأستعار الثابتية (لاجمالي & 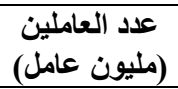 & الاستثمار بالأسعار & الاستثمار بالأسعار & القطاع & السنة \\
\hline 2834.3 & 1.029 & 0.700127 & 345.8 & الزراعة & 1988 \\
\hline 2641.0 & 0.211 & 0.416188 & 162.5 & الصناعة التحويلية & \\
\hline 325.7 & 0.286 & 0.599441 & 285.5 & الكهرباء و الماء & \\
\hline 1527.9 & 1.549 & 0.077667 & 24.9 & البناء والتشييد & \\
\hline 3109.9 & 1.057 & 0.955032 & 471.7 & الزراعة & 1989 \\
\hline 2664.8 & 0.218 & 2.339362 & 913.4 & الصناعة التحويلية & \\
\hline 357.0 & 0.295 & 0.911865 & 434.3 & الكهرباء والماء & \\
\hline 1308.0 & 0.241 & 0.159077 & 51 & البناء والتشييد & \\
\hline 3447.9 & 0.896 & 0.760462 & 375.6 & الزراعة & 1990 \\
\hline 1414.9 & 0.217 & 2.597526 & 1014.2 & الصناعة التحويلية & \\
\hline 207.8 & 0.381 & 0.654031 & 311.5 & الكهرباء و الماء & \\
\hline 1075.0 & 0.288 & 0.180911 & 58 & البناء و التشييد & \\
\hline 2877.2 & 1.017 & 0.350266 & 173.0 & الزراعة & 1991 \\
\hline 538.5 & 0.208 & 0.425152 & 166.0 & الصناعة التحويلية & \\
\hline 164. 1 & 0.277 & 0.159991 & 76.2 & الكهرباء و الماء & \\
\hline 301.5 & 0.253 & 0.046475 & 14.9 & البناء و التشييد & \\
\hline 3531.9 & 1.021 & 2.548642 & 1258.8 & الزراعة & 1992 \\
\hline 550.0 & 0.021 & 2.789869 & 1089.3 & الصناعة التحويلية & \\
\hline 289.6 & 0.285 & 0.832079 & 396.3 & الكهرباء والماء & \\
\hline 347.2 & 0.254 & 0.116968 & 37.5 & البناء و التشييد & \\
\hline 3492.4 & 1.025 & 9.373973 & 4629.9 & الزراعة & 1993 \\
\hline 1323. 2 & 0.205 & 13.40408 & 5233.6 & الصناعة التحويلية & \\
\hline 291.0 & 0.293 & 1.969653 & 938.1 & الكهرباء والماء & \\
\hline 286.2 & 0.255 & 0.169682 & 54.4 & البناء والتشييد & \\
\hline 3741.0 & 1.029 & 17.14988 & 8470.5 & الزراعة & 1994 \\
\hline 1376.6 & 0.203 & 15.84973 & 6188.5 & الصناعة التحويلية & \\
\hline 261.1 & 0.3 & 3.187222 & 1518.0 & الكهرباء والماء & \\
\hline 83.1 & 0.256 & 0.182158 & 58.4 & البناء و التشييا & \\
\hline 4188. 2 & 1.033 & 37.65038 & 18595.9 & الزراعة & 1995 \\
\hline 1601.9 & 0.202 & 74.41983 & 29057.1 & الصناعة التحويلية & \\
\hline 312.9 & 0.355 & 6.520788 & 3105.7 & الكهرباء و الماء & \\
\hline 70.5 & 0.257 & 0.154086 & 49.4 & البناء و التشييد & \\
\hline 4498.3 & 1.036 & 14.50021 & 7161.8 & الزراعة & 1996 \\
\hline 1672.3 & 0.2 & 11.54519 & 4507.8 & الصناعة التحويلية & \\
\hline 340.4 & 0.363 & 4.888124 & 2328.1 & الكهرباء و الماء & \\
\hline 32.6 & 0.259 & 0.143169 & 45.9 & البناء والتشييد & \\
\hline 4133.8 & 1.04 & 36.7 & 18126.5 & الزراعة & 1997 \\
\hline 01821.5 & 0.199 & 33.9 & 13236.2 & الصناعة التحويلية & \\
\hline 345. 0 & 0.371 & 28.9 & 13764.4 & الكهرباء والماء & \\
\hline 50.2 & 0.26 & 1 & 320.6 & البناء و التشييد & \\
\hline 4475. 1 & 1.044 & 10.57581 & 5223.5 & الزراعة & 1998 \\
\hline 1840.6 & 0.197 & 27.06453 & 10567.3 & الصناعة التحويلية & \\
\hline 328.4 & 0.379 & 6.138237 & 2923.5 & الكهرباء والماء & \\
\hline 70.8 & 0.261 & 2.709233 & 868.58 & البناء والتشييد & \\
\hline 5188.3 & 1.05 & 36.47729 & 18016.5 & الزراعة & 1999 \\
\hline 1951.0 & 0.195 & 83.26735 & 32511.6 & الصناعة التحويلية & \\
\hline 303.8 & 0.387 & 34.55847 & 16459.4 & الكهرباء والماء & \\
\hline 90.4 & 0.263 & 1.370555 & 439.4 & البناء و التشييد & \\
\hline 4913. 2 & 1.054 & 51.1087 & 25243.1 & الزراعة & 2000 \\
\hline 1863.7 & 0.193 & 185.2229 & 72320.0 & الصناعة التحويلية & \\
\hline 304.9 & 0.395 & 160.6652 & 76521.1 & الكهرباء والماء & \\
\hline 134.5 & 0.265 & 1.6335 & 523.7 & البناء و التشييد & \\
\hline
\end{tabular}




\section{6 العدد 6}

\section{ناثير استققرارية بـعض الانشطة السلعية في العراق على تقدير نماذج}

\section{البيانات المقطعية للفترة (1988-2000)}

المبحث الثاني/ الجانب النظري

2-1 السلاسل غير الساكنة والعمليات المتكاملة فيلة فئل

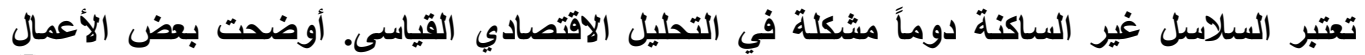

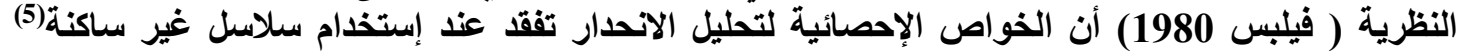
ويعطي إنحار وهمي للعلاقات تحت التقاير.

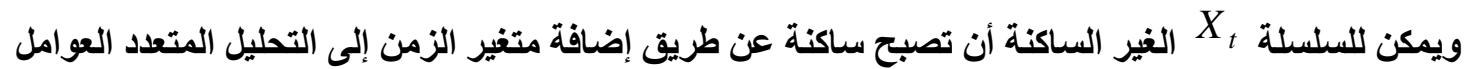

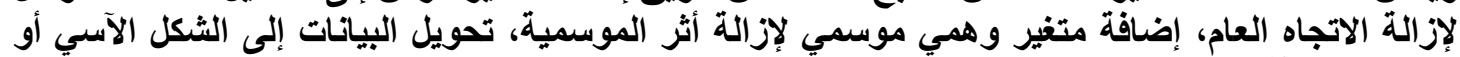

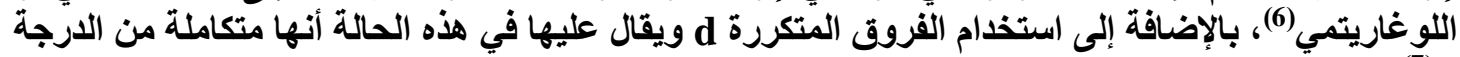
$X_{t} \sim I(d)$

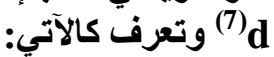

فمثلاً، إذا كانت $x_{t}=I(1)$ فإن الفرق الأول يعطي سلسلة ساكنة كالآتي: $\Delta x_{t}=x_{t}-x_{t-1}$

أما إذا كانت

$\Delta^{2} x_{t}=\left(x_{t}-x_{t-1}\right)-\left(x_{t-1}-x_{t-2}\right)-------$

$=x_{t}-2 x_{t-1}+x_{t-2}$

2-2

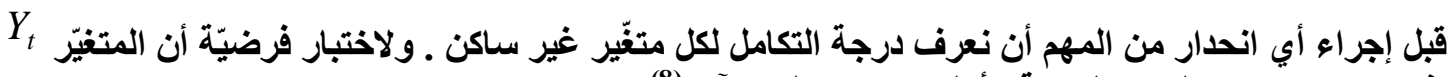
غير موسمى متكامل من الارجة الأولى وكان فرف درجة الدولد كالآتي (8): $Y_{t}=Y_{t-1}+\varepsilon_{t}$

$$
\text { حيث }
$$

$Y_{t}=\rho Y_{t-1}+\varepsilon_{t}------------0(6)$

إذا كانت قيمة م تساوي الواحد الصحيح فإن السلسلة y تكون غير ساكنة، عند تطبيق المربعات الصغرى العادية على المعادلة (6) و اختبار الفرض

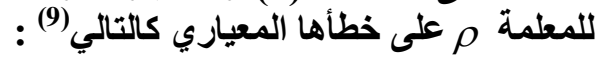
$t=\frac{\hat{\rho}}{S E_{\hat{\rho}}}$

فإن توزيع t في المعادلة (7) ليس مطابقاً للتوزيع المعروف لهذا تم إثتقاق جداول عديدة مثل جدول

(10)Mackinon(1991 Guilkey \& Schmidt(1989) و Fuller(1976)

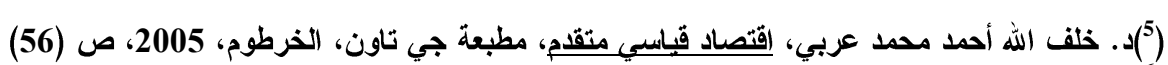

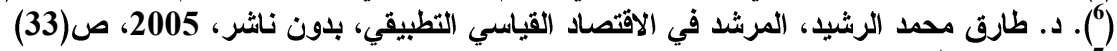

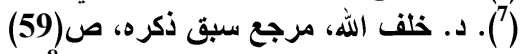

$\left({ }^{8}\right)$. RICHARD HARRIS, pp(24)

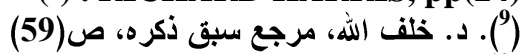

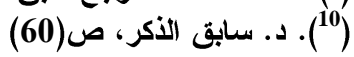




\section{6 العدد 66}

تاثير استنقرارية بـعض الانشطة السلعية في العراق على تقدير نماذج

$$
\text { البيانات المقطعية للفترة (1988-2000) }
$$

Dickey Fuller (DF) 2-3 اختبار ديكي - فوللر التران

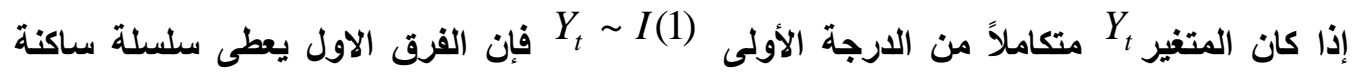

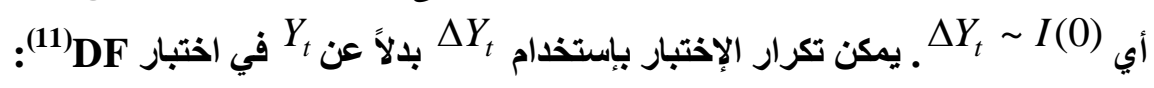
$\Delta Y_{t}=\delta Y_{t}+\varepsilon_{t}----------(8)$

ومرة أخرى ينصب إهتمامنا على القيمة السالبة للمعلمة ס. إذا رفض فرض العدم و و كان الفرض

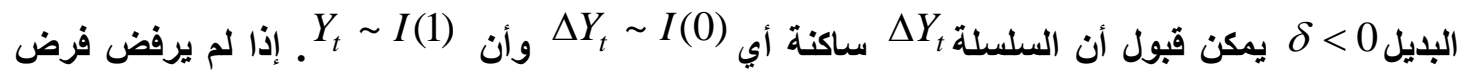

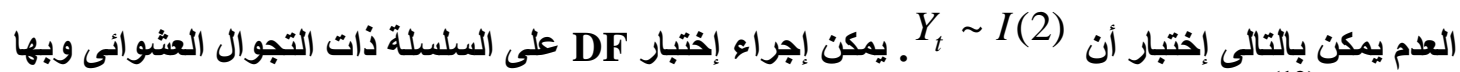
$\Delta Y_{t}=\mu+\delta Y_{t-1}+\varepsilon_{t}-------(9)$ وان نقطة الضعف الوحيدة لإختبار DF الأصلى هو أن هذا الإختبار لا يأخذ في الحسبان الارتباط الذاتي لعنصر

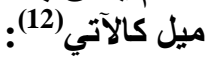

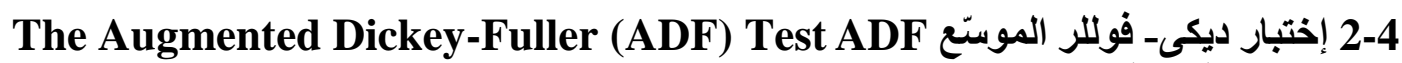

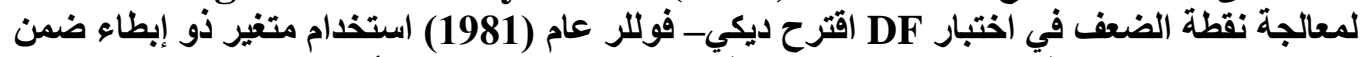

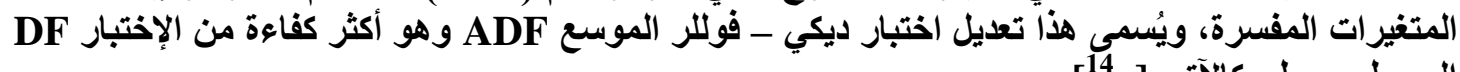
$\Delta Y_{t}=\delta Y_{t-1}+\sum_{i=1}^{n} \theta_{i} \Delta Y_{t-i}+\varepsilon_{t}$

$\mathbf{H}_{0}: \delta=\mathbf{0}$

حيث يتم اختبار الفرضية التالية:-

فاذا تم قبول فرضية العدم ، هذا يعني وجود جذر وحدة في السلسلة الزمنية ـوقد تم استخدام اختبار ديكي فولر

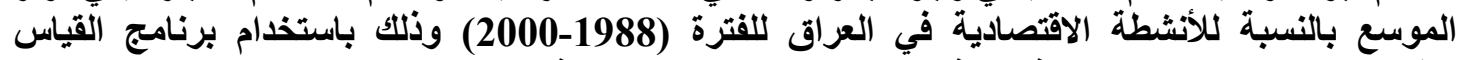

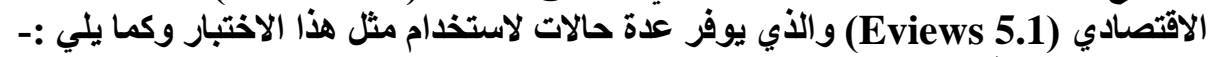

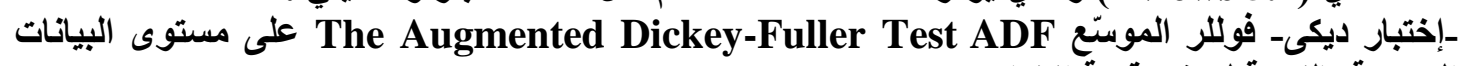

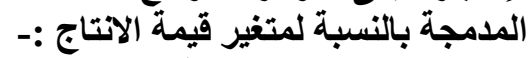

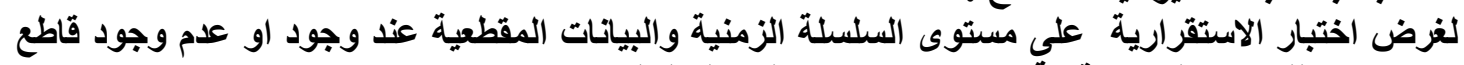

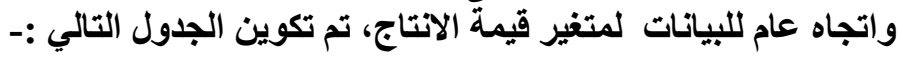




\section{6 العدد 6}

تاثير استنقرارية بـعض الانشطة السلعية في العراق على تقدير نماذج

$$
\text { البيانات المقطعية للفترة (1988-2000) }
$$

$$
\text { جدول ( } 2 \text { ) }
$$

- إختبار ديكى- فوللر الموستع The Augmented Dickey-Fuller Test ADF على مستوى البيانات

\begin{tabular}{|c|c|c|c|c|c|c|}
\hline \multicolumn{2}{|c|}{ علم وجود قاطع واتجاه عام } & \multicolumn{2}{|c|}{ عند وجود قاطع واتجاه عام } & \multicolumn{2}{|c|}{ عند وجود قاطع } & الاختبار \\
\hline الاحتمالية & قيمة الاختبار & القيمة الاحتمالية & قيمة الاختبار & القيمة الاحتمالية & قيمة الاختبار & ذذ \\
\hline 0.6304 & 6.15052 & $15 * * 0.0031$ & 23.1864 & 0.1129 & 12.9689 & ADF \\
\hline
\end{tabular}
المدمجة بالنسبة لمتغير قيمة الاتتاج

يلاحظ من الجدول (2 ) بان السلسلة المقطعية للبيانات مستقرة عند وجود قاطع واتجاه عام وذلك لكون القيمة

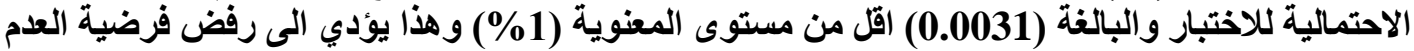

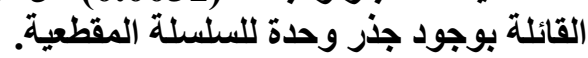

- إختبار ديكى- فوللر الموستع The Augmented Dickey-Fuller Test ADF على مستوى الفروق

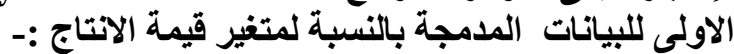

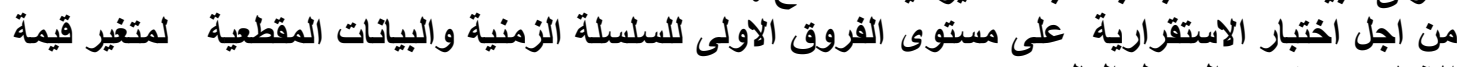

$$
\text { جلول (3) (3) }
$$

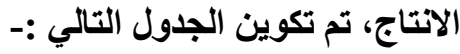

\begin{tabular}{|c|c|c|c|c|c|c|}
\hline \multicolumn{2}{|c|}{ علم وجود قاطع واتجاه عام } & \multicolumn{2}{|c|}{ عند وجود قاطع واتجاه عام } & \multicolumn{2}{|c|}{ عند وجود قاطع } & \multirow[t]{2}{*}{ الاختبار } \\
\hline الاحتمالية & قيمة الاختبار & القيمة الاحتمالية & قيمة الاختبار & الاحتمالية & قيمة الاختبار & \\
\hline$* * \mathbf{0 . 0 0 0 0}$ & 42.5463 & $* * 0.0048$ & 22.0634 & $* * 0.0003$ & 29.3392 & ADF \\
\hline
\end{tabular}

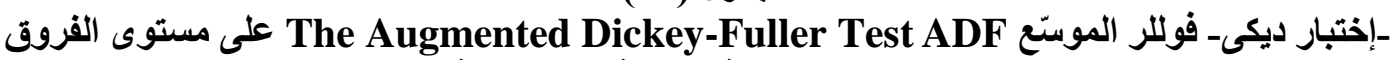
الاولى للبيانات المدمجة بالنسبة لمتغير قيمة الانتاج

يلاحظ من الجدول ( 3 ) بان السلسلة المقطعية للبيانات مستقرة عند وجود او عدم وجود قاطع واتجاه عام.

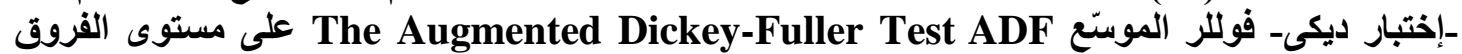

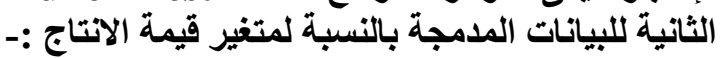
لغرض اختبار الاستقرارية على مستوى الفروقئ الثانية الثانية للسلسلة الزمنية والبيانات المقطعية لمتفير قيمة الاتتاج، تم تكوين الجدول التالي :- 


$$
66 \text { العدد } 66
$$

تاثير استقرارية بـعض الانشطة السلعية في العراق على تقدير نماذف

$$
\text { البيانات المقطعية للفترة (1988-2000) }
$$

جدول ( 4 )

-إختبار ديكى- فوللر الموستع The Augmented Dickey-Fuller Test ADF على مستوى الفروق

\begin{tabular}{|c|c|c|c|c|c|c|}
\hline \multicolumn{2}{|c|}{ عدم وجود قاطع واتجاه عام } & \multicolumn{2}{|c|}{ عند وجود قاطع واتجاه عام } & \multicolumn{2}{|c|}{ عند وجود قاطع } & \multirow[t]{2}{*}{ الاختبار } \\
\hline الاحتمالية & قيمة الاختبار & القيمة الاحتمالية & قيمة الاختبار & القيمة الاحتمالية & قيمة الاختبار & \\
\hline$* * 0.000$ & 76.8495 & $* * 0.0000$ & 34.977 & $* * 0.000$ & 44.6145 & ADF \\
\hline
\end{tabular}
الثانية للبيانات المدمجة بالنسبة لمتغير قيمة الانتاج

يلاحظ من الجدول ( 4 ) بان السلسلة المقطعية للبيانات مستقرة عند وجود او عدم وجود قاطع واتجاه عام. -إختبار ديكى- فوللر الموستع The Augmented Dickey-Fuller Test ADF على مستوى البيانات المدمجة بالنسبة لمتغير عدار العزب العمال:لغرض اختبار الاستقرارية على عستوى السلسلة الزمنية والبيانات المقطعية لمتغير عدد العمال، تم تكوين

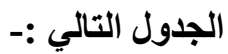

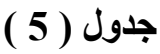

-إختبار ديكى- فوللر الموستع The Augmented Dickey-Fuller Test ADF على مستوى ( البيانات

\begin{tabular}{|c|c|c|c|c|c|c|}
\hline \multicolumn{2}{|c|}{ عدم وجود قاطع واتجاه عام } & \multicolumn{2}{|c|}{ عند وجود قاطع واتجاه عام } & \multicolumn{2}{|c|}{ عند وجود قاطع } & الاختبار \\
\hline الاحتمالية & قيمة الاختبار & القيمة الاحتمالية & قيمة الاختبار & القيمة الاحتمالية & قيمة الاختبار & \\
\hline 0.3574 & 8.82353 & $* * \mathbf{0 . 0 0 0}$ & 34.8203 & $* * 0.0052$ & 21.8292 & ADF \\
\hline
\end{tabular}
المدمجة بالنسبة لمتغير عدد العمال

من الجدول ( 5 ) نلاحظ بان السلسلة المقطعية للبيانات مستقرة عند وجود قاطع واتجاه عام مع القاطع. -إختبار ديكى- فوللر الموستّ المانع The Augmented Dickey-Fuller Test ADF على مستوى الفروق الاولى للبيانات المدمجة بالنسبة لمتفير المئي عدد العمال:-

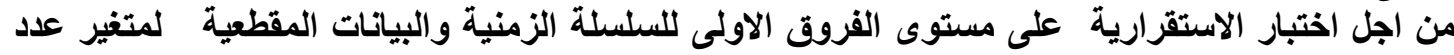

جدول (6 )

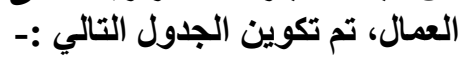

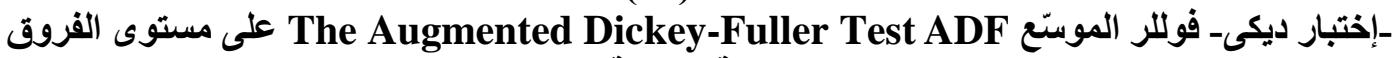

\begin{tabular}{|c|c|c|c|c|c|c|}
\hline \multicolumn{2}{|c|}{ علم وجود قاطع واتجاه عام } & \multicolumn{2}{|c|}{ عند وجود قاطع واتجاه عام } & \multicolumn{2}{|c|}{ عند وجود قاطع } & الاختبار \\
\hline الاحتمالية & قيمة الاختبار & القيمة الاحتمالية & قيمة الاختبار & القيمة الاحتمالية & قيمة الاختبار & \\
\hline$* * 0.0000$ & 64.3934 & $* * 0.000$ & 47.07832 & $* * 0.0000$ & 55.4971 & ADF \\
\hline
\end{tabular}
الاولى للبيانات المدمجة بالنسبة لمتغير عدد العمال

من الجدول ( 6 ) نلاحظ بان السلسلة المقطعية للبيانات مستقرة عند وجود او عدم وجود قاطع واتجاه عام مع -إختبار ديكى- فوللر الموستع The Augmented Dickey-FullerTest ADF على مستوى الفروق

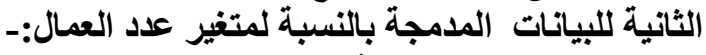

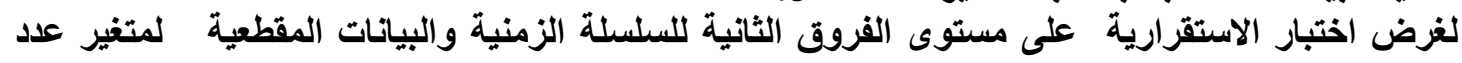

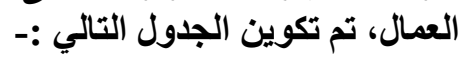




$$
66 \text { العدد } 60
$$

تاثير استقرارية بعضر الانشطة السلعية في العراق على تقدير نماذج

$$
\text { البيانات المقطعية للفترة (1988-2000) }
$$

جدول (7 )

- إختبار ديكى- فوللر الموستع The Augmented Dickey-FullerTest ADF على مستوى الفروق

\begin{tabular}{|c|c|c|c|c|c|c|}
\hline \multicolumn{2}{|c|}{ عدم وجود قاطع واتجاه عام } & \multicolumn{2}{|c|}{ عند وجود قاطع واتجاه عام } & \multicolumn{2}{|c|}{ عند وجود قاطع } & \multirow[t]{2}{*}{ الاختبار } \\
\hline الاحتمالية & قيمة الاختبار & الاحتمالية & قيمة الاختبار & الاحتمالية & الاختبار & \\
\hline$* * 0.000$ & 72.4072 & $* * 0.000$ & 41.8073 & $* * 0.0000$ & 57.6886 & ADF \\
\hline
\end{tabular}

الثانية للبيانات المدمجة بالنسبة لمتغير عدد العمال

من الجدول ( 7 ) نلاحظ بان السلسلة المقطعية للبيانات مستقرة عند وجود او عدم وجود قاطع واتجاه عام مع

-إختبار ديكى- فوللر الموستع The Augmented Dickey-Fuller Test ADF على مستوى البيانات

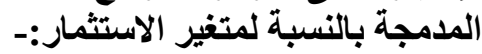

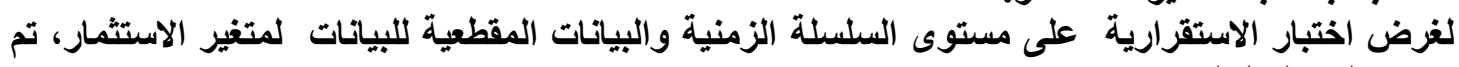

جدول ( ) 8 )

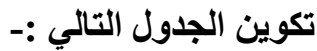

-إختبار ديكى- فوللر الموستع The Augmented Dickey-Fuller Test ADF على مستوى البيانات

\begin{tabular}{|c|c|c|c|c|c|c|}
\hline \multicolumn{2}{|c|}{ عدم وجود قاطع واتجاه عام } & \multicolumn{2}{|c|}{ عند وجود قاطع واتجاه عام } & \multicolumn{2}{|c|}{ عند وجود قاطع } & \multirow[t]{2}{*}{ الاختبار } \\
\hline الاحتمالية & قيمة الاختبار & الاحتمالية & قيمة الاختبار & الاحتمالية & الاختبار & \\
\hline 0.8712 & 3.84058 & 0.4437 & 7.89578 & 0.9959 & 1.26908 & ADF \\
\hline
\end{tabular}
المدمجة بالنسبة لمتغير الاستثمار

من الجدول ( 8 ) نلاحظ بان السلسلة المقطعية للبيانات مستقرة عند وجود او عدم وجود قاطع واتجاه عام مع

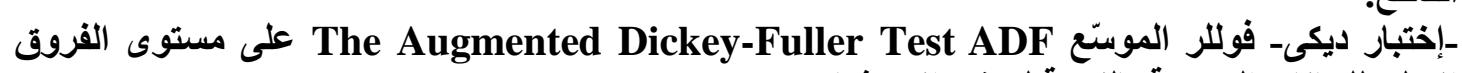

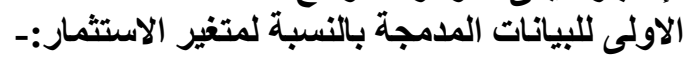

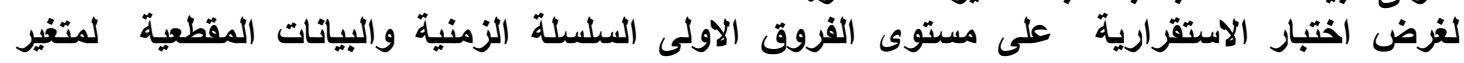

جدول ( 9 ( )

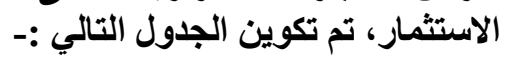

- إختبار ديكى- فوللر الموستع The Augmented Dickey-Fuller Test ADF على مستوى الفروق

\begin{tabular}{|c|c|c|c|c|c|c|}
\hline \multicolumn{2}{|c|}{ عدم وجود قاطع واتجاه عام } & \multicolumn{2}{|c|}{ عند وجود قاطع واتجاه عام } & \multicolumn{2}{|c|}{ عند وجود قاطع } & \multirow[t]{2}{*}{ الاختبار } \\
\hline الاحتمالية & قيمة الاختبار & الاحتمالية & قيمة الاختبار & الاحتمالية & الاختبار & \\
\hline$* * 0.0009$ & 26.4614 & 0.0959 & $\mathbf{1 3 . 4 9 4 3}$ & $16 * 0.0205$ & 18.0981 & ADF \\
\hline
\end{tabular}
الاولى للبيانات المدمجة بالنسبة لمتغير الاستثمار

من الجدول ( 9 ) نلاحظ بان السلسلة المقطعية للبيانات مستقرة عند وجود قاطع و عدم وجود قاطع واتجاه

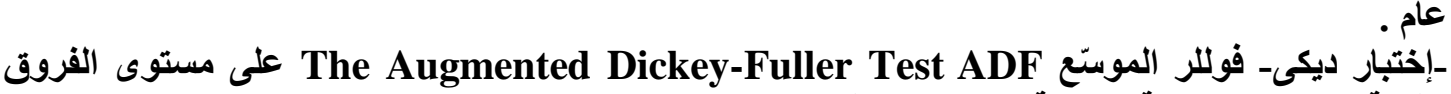

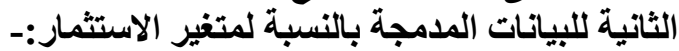

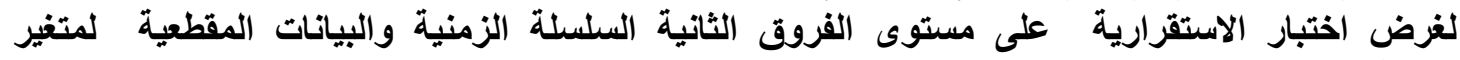

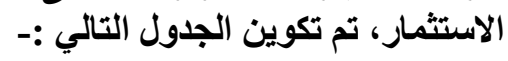




\section{6 العدأ 66}

تاثير استنقرارية بـعض الانشطة السلعية في العراق على تقدير نماذج

$$
\text { البيانات المقطعية للفترة (1988-2000) }
$$

جدول (10)

-إختبار ديكى- فوللر الموستع The Augmented Dickey-Fuller Test ADF جلى مستوى الفروق

\begin{tabular}{|c|c|c|c|c|c|c|}
\hline \multicolumn{2}{|c|}{ عدم وجود قاطع واتجاه عام } & \multicolumn{2}{|c|}{ عند وجود قاطع واتجاه عام } & \multicolumn{2}{|c|}{ عند وجود قاطع " عن } & \multirow[t]{2}{*}{ الاختبار } \\
\hline الاحتمالية & قيمة الاختبار & القيمة الاحتمالية & قيمة الاختبار & القيمة الاحتمالية & قيمة الاختبار & \\
\hline$* * 0.0000$ & 52.8725 & $* 0.0139$ & 19.1837 & $* * 0.0002$ & 29.8224 & ADF \\
\hline
\end{tabular}

من الجدول ( 10 ) نلاحظ بان السلسلة المقطعية للبيانات مستقرة عند وجود او عدم وجود قاطع واتجاه عام مع القاطع.

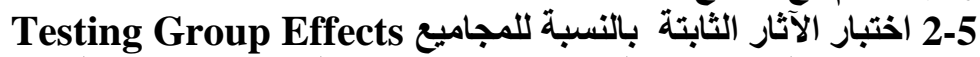
لاختبار فرضية العدم القائلة بان جميع الآثار الثابتة للمجاميع مساوية إلى الصفر أي إن

$$
H_{0}: \mu_{1}=\ldots=\mu_{n-1}=0
$$

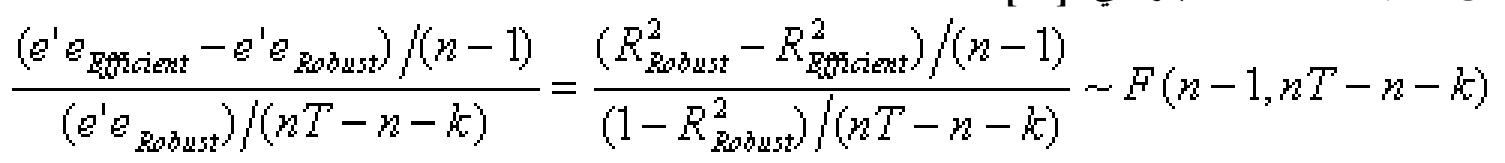

فإذا تم رفض فرضية العدم هذا معناه بان الآثار بالنسبة للمجاميع معنوية أي إن نموذج الآثار الثابتة للمجاميع أفضل من نموذج رفض فرضية الأمج بين البيانات المقطعية وان السلاسل بالسبة الزمنية.

1717 Wooldridge, Jeffrey M. (2002). Econometric Analysis of Cross Section and Panel Data, Cambridge, MA: The MIT Press.p148 


\section{6 العدد 66}

تاثير استنقرارية بـعض الانشطة السلعية في العراق على تقدير نماذج

$$
\text { البيانات المقطعية للفترة (1988-2000) }
$$

Testing Group Effects

2-6 اختبار الآثار الثابتة بالنسبة للقترات

H:t1=t2=....... =tn-1=0

$\frac{\left(e^{\prime} e_{\text {Efficient }}-e^{\prime} e_{\text {Robust }}\right) /(T-1)}{\left(e^{\prime} e_{\text {Robust }}\right) /(T n-T-k)} \sim F(T-1, T n-T-k)$

فان الصيغة العامة للاختبار هي:

فإذا تم رفض فرضية العدم هذا معناه بان الآثار بالنسبة للفترات معنوية أي إن نموذج الآثار الثابتة للفترات

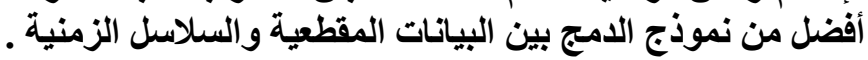

2-7 اختبار الآثار الثابتة بالنسبة للفترات والمجاميع Testing Group Effects لاختبار فرضية العدم القائلة بان جميع الآثار الثابتة للفترات الثات والمجاميع مساوية إلى الصفر أي إن

$$
H_{0}: \mu_{1}=\ldots=\mu_{n-1}=0 \tau_{1}=\ldots=\tau_{T-1}=0
$$

فان ألصيغه ألعامـه للاختبار هي:

$$
\text { F-test: } \frac{\left(e^{\prime} e_{E \text { ffficient }}-e^{\prime} e_{\text {Rabust }}\right) /(n+T-2)}{\left(e^{\prime} e_{\text {Rabust }}\right) /(n T-n-T-k+1)} \sim F[(n+T-2),(n T-n-T-k+1)]
$$

فإذا تم رفض فرضية العدم هذا معناه بان الآثار بالنسبة للفترات والمجاميع معنوية أي إن نموذج الآثار

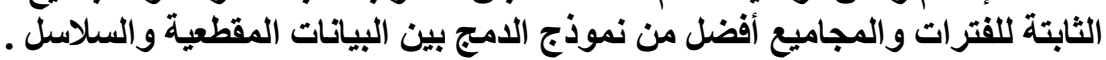




\section{6 العدد 66}

\section{تاثير استقرارية بـعض الانشطة السلعية في العراق على تقدير نماذف \\ البيانات المقطعية للفترة (1988-2000)}

pooled least square أسلوب المربعات الصغرى المدمجة في التقدير المبردير

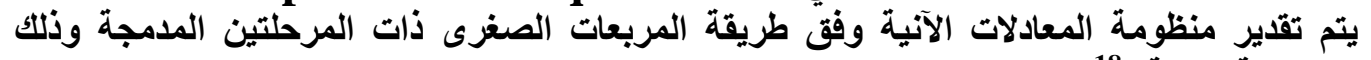

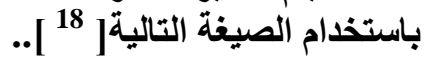
$\hat{\beta}_{I V}=\left(\sum_{i} X_{i}^{\prime} P_{Z_{i}} X_{i}\right)^{-1}\left(\sum_{i} X_{i}^{\prime} P_{Z_{i}} Y_{i}\right)$

年: $P_{Z_{i}}=\left(Z_{i}\left(Z_{i}^{\prime} Z_{i}\right)^{-1} Z_{i}^{\prime}\right)$ 2-9 أسلوب المربعات الصغرى المدمجة في التقدير باستخدام الآثار الثابتة Fixed pooled least square effect

$\hat{\beta}_{I V}=\left(\sum_{i} X_{i} Q P_{\tilde{Z}_{i}} Q X_{i}\right)^{-1}\left(\sum_{i} X_{i}^{\prime} Q P_{\tilde{Z}_{i}} Q Y_{i}\right)$

$\tilde{Z}_{i}=Q Z_{i}$ 


$$
66 \text { العدد }
$$

تاثير استقرارية بعضر الانشطة السلعية في العراق على تقدير نماذج

$$
\text { البيانات المقطعية للفترة (1988-2000) }
$$

$$
\text { الباب الثالث/ الجاتب التطبيقي }
$$

$$
\text { 3-1 عرض وتحليل ومناقثة النتائج:- }
$$

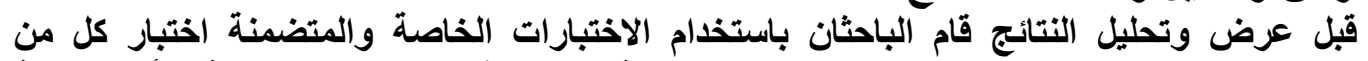
(Redundant fixed effect ,Hausman test)

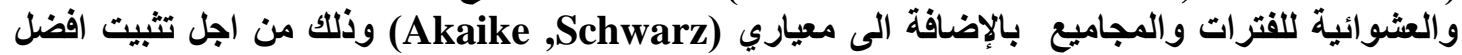

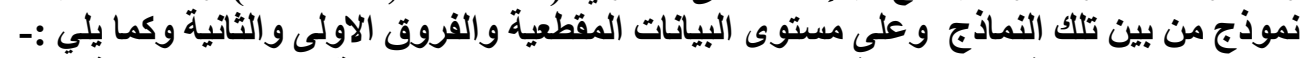

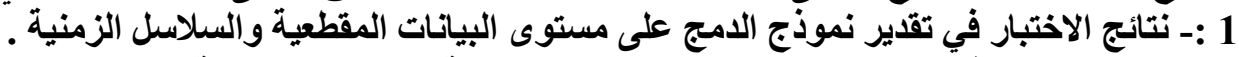

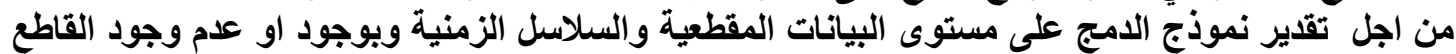

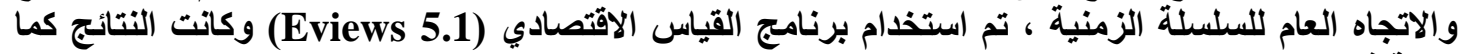

\begin{tabular}{|c|c|c|c|}
\hline عدم وجود قاطع واتجاه & بوجود قاطع واتجاه عام & بوجود قاطع & الاختبار \\
\hline 2.337390 & $\mathbf{1 . 1 8 6 7 1 5}$ & 1.990470 & Akaike info criterion \\
\hline 2.688240 & 1.537565 & 2.341320 & Schwarz criterion \\
\hline
\end{tabular}

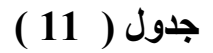

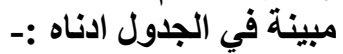

نتائج الاختبار في تقدير نموذج الدمج على مستوى البيانات المقطعية والسلاسل الزمنية .

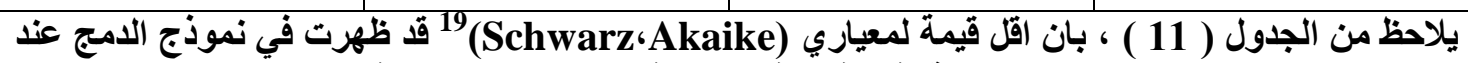

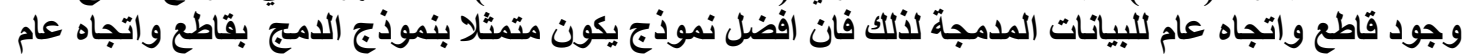

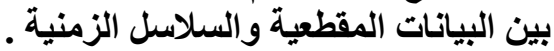

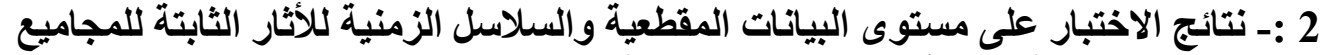

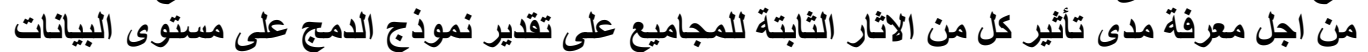

\begin{tabular}{|c|c|c|c|c|c|c|}
\hline \multicolumn{2}{|c|}{ عدم وجود قاطع واتجاه عام } & \multicolumn{2}{|c|}{ بوجود قاطع واتجاه عام } & \multicolumn{2}{|c|}{ بوجود قاطع } & \multirow{2}{*}{ الاختبار } \\
\hline الاحتمالية & $\mathbf{F}$ & الاحتمالية & $\mathbf{F}$ & الاحتمالية & $\mathbf{F}$ & \\
\hline$* * 0.0074$ & 4.594478 & 0.3615 & 1.097155 & 0.6235 & 0.592574 & $\begin{array}{r}\text { Redundant Fixed } \\
\text { Effects Tests }\end{array}$ \\
\hline \multicolumn{2}{|c|}{2.048866} & \multicolumn{2}{|c|}{1.280082} & \multicolumn{2}{|c|}{$\frac{1}{1.962777}$} & Akaike info criterion \\
\hline \multicolumn{2}{|c|}{2.499153} & \multicolumn{2}{|c|}{1.730369} & \multicolumn{2}{|c|}{2.413064} & Schwarz criterion \\
\hline
\end{tabular}

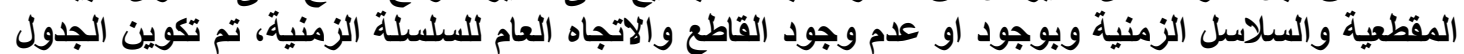

$$
\text { جدول ( } 12 \text { ( } 12 \text { ) }
$$$$
\text { الاتي :- }
$$

نتائج الاختبار على مستوى البيانات المقطعية والسلاسل الزمنية للأثار الثابتة للمجاميع

19 "للمزيد من التفاصيل حول المعيارين (Schwarz،Akaike) يرجى مراجعة 'Ben "Econometrics theory and application with eviews "2005, Printed and bound in MaJaysia ,ch.14 


\section{6 الكعد 6}

تاثير استقرارية بعضر الانشطة السلعية في العراق على تقدير نماذج

$$
\text { البيانات المقطعية للفترة (1988-2000) }
$$

يلاحظ من الجدول ( 12 ) ، بان الاثار الثابتة للمجاميع كاتت معنوية في حالة عدم وجود قاطع واتجاه

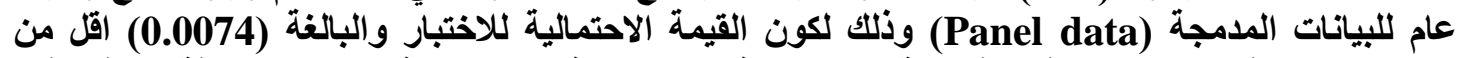

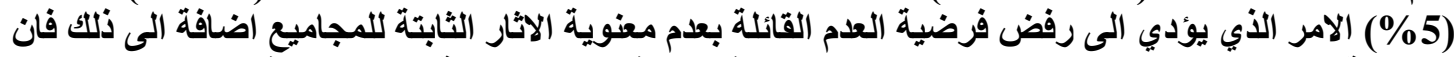

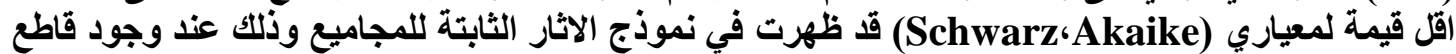

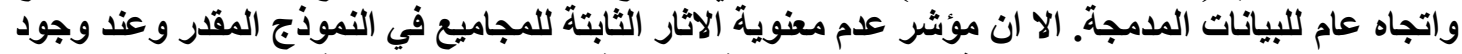

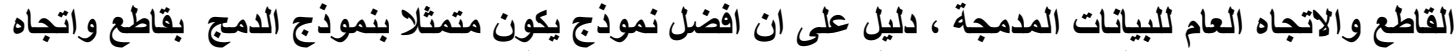

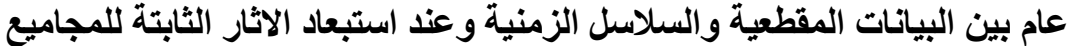

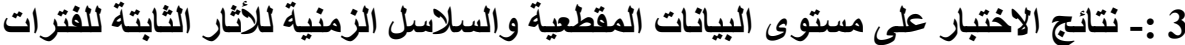

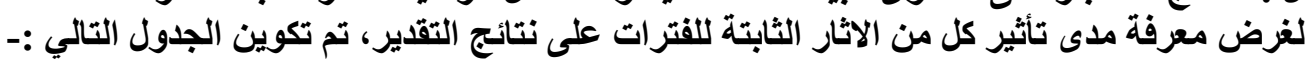
جدول (13 ) 13 )

نتائج الاختبار على مستوى البيانات المقطعية والسلاسل الزمنية للأثار الثابتة للفترات

\begin{tabular}{|c|c|c|c|c|c|c|}
\hline \multicolumn{2}{|c|}{ عدم وجود قاطع واتجاه } & \multicolumn{2}{|c|}{ بوجود قاطع واتجاه عام } & \multicolumn{2}{|c|}{ بوجود قاطع } & \multirow[t]{2}{*}{ الاختبار } \\
\hline الاحتمالية & $\mathbf{F}$ & الاحتمالية & $\mathbf{F}$ & الاحتمالية القيمة & $\mathbf{F}$ & \\
\hline$* 0.0180$ & 2.547069 & 0.1809 & 1.489636 & 0.2063 & 1.427057 & $\begin{array}{r}\text { Redundant Fixed } \\
\text { Effects Tests }\end{array}$ \\
\hline \multicolumn{2}{|c|}{2.005002} & \multicolumn{2}{|c|}{1.250020} & \multicolumn{2}{|c|}{1.912607} & Akaike info criterion \\
\hline \multicolumn{2}{|c|}{2.793004} & \multicolumn{2}{|c|}{2.038023} & \multicolumn{2}{|c|}{2.700609} & Schwarz criterion \\
\hline
\end{tabular}

يلاحظ من الجدول ( 13 ) ، بان الاثار الثابتة للفترات كاتت معنوية في حالة عدم وجود قاطع واتجاه

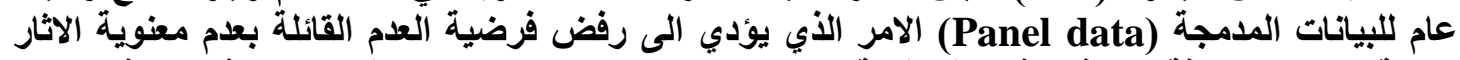

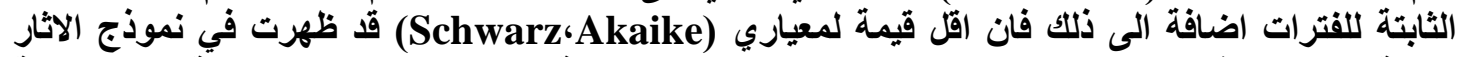

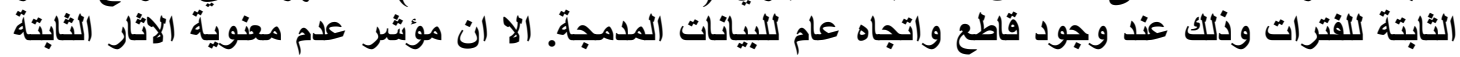

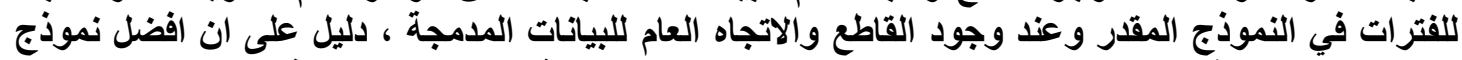

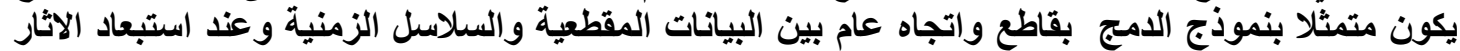

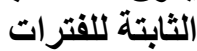

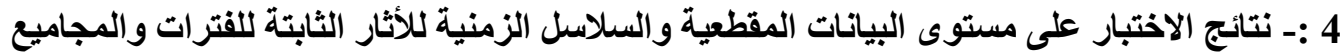

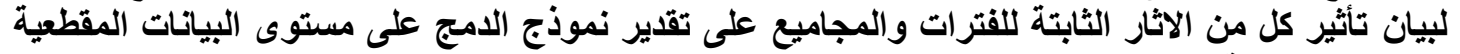
والسلاسل الزمنية ، تم تكوين الجدول التالئ :- 


\section{6 العدد 6}

تاثير استنقرارية بـعض الانشطة السلعية في العراق على تقدير نماذج

$$
\text { البيانات المقطعية للفترة (1988-2000) }
$$

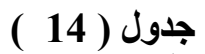

4 :- نتائج الاختبار على مستوى البيانات المقطعية والسلاسل الزمنية للأثار الثابتة للفترات والمجاميع

\begin{tabular}{|c|c|c|c|c|c|c|}
\hline \multicolumn{2}{|c|}{ عدم وجود قاطع واتجاه عام } & \multicolumn{2}{|c|}{ بوجود قاطع واتجاه عام } & \multicolumn{2}{|c|}{ بوجود قاطع } & \multirow[t]{2}{*}{ الاختبار } \\
\hline الاحتمالية & $\mathbf{F}$ & الاحتمالية & $\mathbf{F}$ & الاحتمالية & $\mathbf{F}$ & \\
\hline *0.0111 & 2.706960 & $* 0.0351$ & 2.195261 & 0.3087 & 1.228457 & $\begin{array}{r}\text { Redundant Fixed } \\
\text { Effects Tests }\end{array}$ \\
\hline \multicolumn{2}{|c|}{1.910338} & \multicolumn{2}{|c|}{1.043193} & \multicolumn{2}{|c|}{1.962126} & Akaike info criterion \\
\hline \multicolumn{2}{|c|}{2.810912} & \multicolumn{2}{|c|}{1.943767} & \multicolumn{2}{|c|}{2.862700} & Schwarz criterion \\
\hline
\end{tabular}

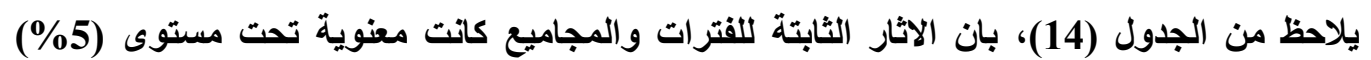

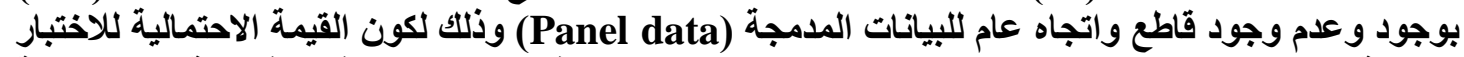

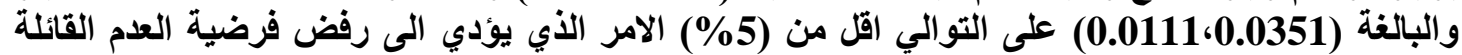

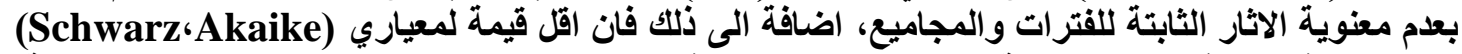

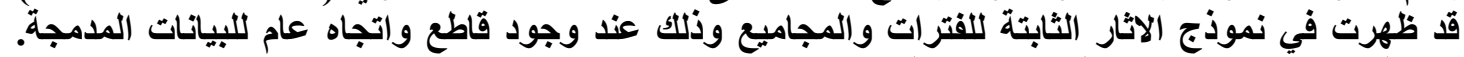

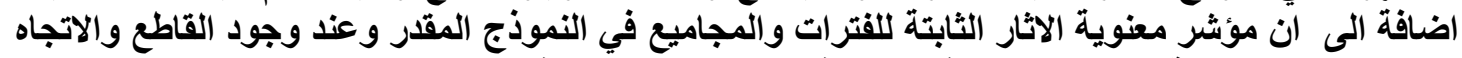

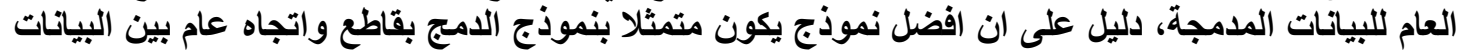

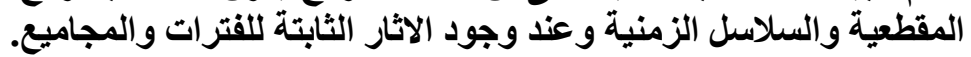

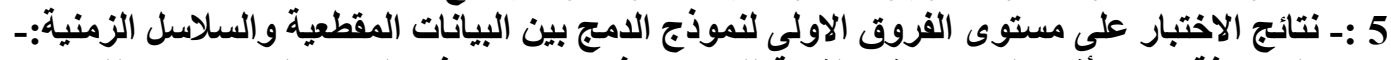

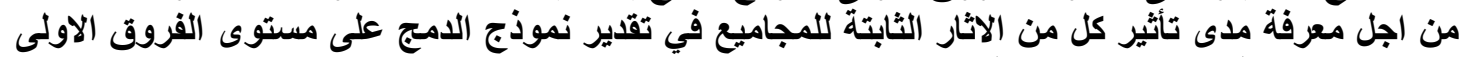

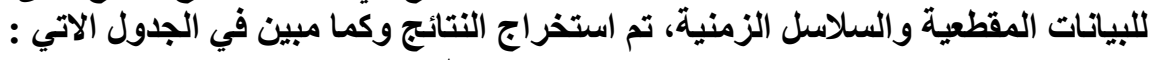

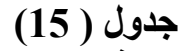

نتائج الاختبار على مستوى الفروق الاولى لنموذج الامتج بين البيانات المقطعية والسلاسل الزمنية:-

\begin{tabular}{|c|c|c|c|}
\hline عدم وجود قاطع واتجاه عام & بوجود قاطع واتجاه عام & بوجود قاطع & الاختبار \\
\hline 0.776798 & 1.070933 & 1.204443 & $\begin{array}{l}\text { Akaike info } \\
\text { criterion }\end{array}$ \\
\hline 0.883748 & 1.435881 & 1.569391 & Schwarz criterion \\
\hline
\end{tabular}

يلاحظ من الجدول (15)، بان اقل قيمة لمعياري (Schwarz‘Akaike) قد ظهرت في نموذج الدمج

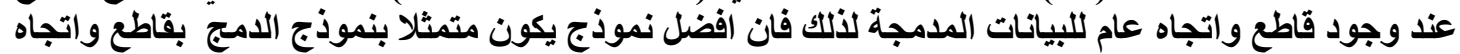
عام بين البيانات المقطعية والسلاسل الزمنية المنية . 


\section{6 العدد 6}

تاثير استنقرارية بـعض الانشطة السلعية في العراق على تقدير نماذج

$$
\text { البيانات المقطعية للفترة (1988-2000) }
$$

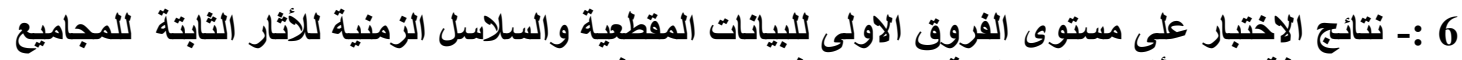

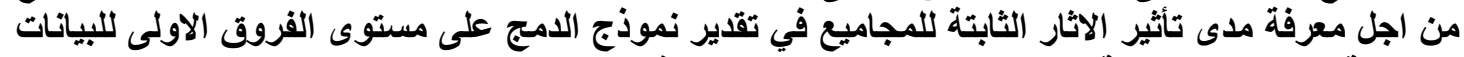

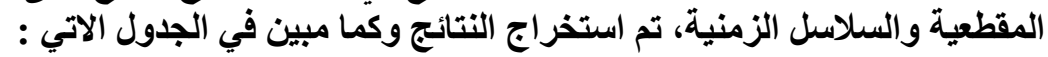

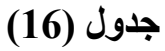

نتائج الاختبار على مستوى الفروق الاولى للبيانات المقطعية والسلاسل الزمنية للأثار الثابتة للمجاميع

\begin{tabular}{|c|c|c|c|c|c|c|}
\hline \multicolumn{2}{|c|}{ عدم وجود قاطع واتجاه عام } & \multicolumn{2}{|c|}{ بوجود قاطع واتجاه عام } & \multicolumn{2}{|c|}{ بوجود قاطع } & \multirow[t]{2}{*}{ الاختبار } \\
\hline الاحتمالية & $\mathbf{F}$ & الاحتمالية & $\mathbf{F}$ & الاحتمالية & $\mathbf{F}$ & \\
\hline 0.1604 & 1.823215 & 0.9789 & 0.063295 & 0.4006 & 1.007703 & $\begin{array}{r}\text { Redundant Fixed } \\
\text { Effects Tests }\end{array}$ \\
\hline \multicolumn{2}{|c|}{0.879495} & \multicolumn{2}{|c|}{1.123297} & \multicolumn{2}{|c|}{1.155088} & Akaike info criterion \\
\hline \multicolumn{2}{|c|}{1.347295} & \multicolumn{2}{|c|}{1.591097} & \multicolumn{2}{|c|}{1.622889} & Schwarz criterion \\
\hline
\end{tabular}

يلاحظ من الجدول (16)، بان الاثار الثابتة للمجاميع كانت غير معنوية في حالة وجود وعدم وجود

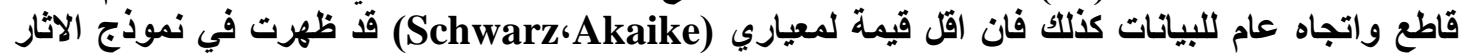

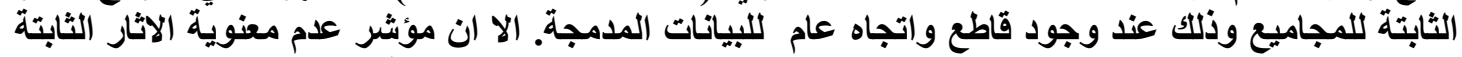

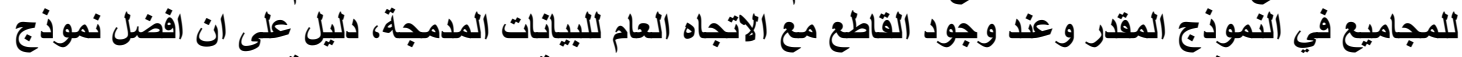

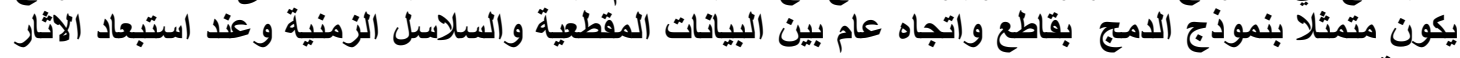
الثابتة للمجاميع مئون

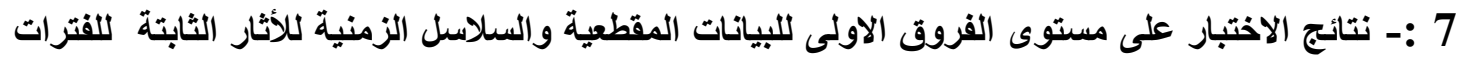

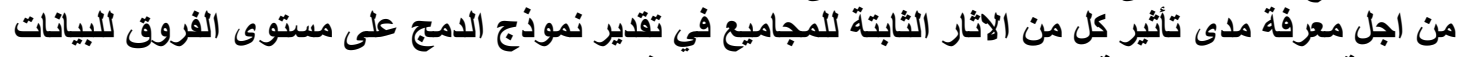

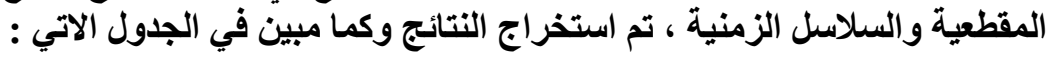

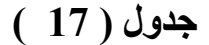

نتائج الاختبار على مستوى الفروق الاولى للبيانات المقطعية والسلاسل الزمنية للأثار الثابتة للفترات

\begin{tabular}{|c|c|c|c|c|c|c|}
\hline \multicolumn{2}{|c|}{ عدم وجود قاطع واتجاه عام } & \multicolumn{2}{|c|}{ بوجود قاطع واتجاه عام } & \multicolumn{2}{|c|}{ بوجود قاطع } & \multirow[t]{2}{*}{ الاختبَر } \\
\hline القيمة الاحتمالية & $\mathbf{F}$ & القيمة الاحتمالية & $\mathbf{F}$ & الاحتمالية & $\mathbf{F}$ & \\
\hline 0.2784 & 1.293906 & $\mathbf{0 . 0 1 7 3}^{*}$ & 2.677435 & 0.0189* & 2.63283 & $\begin{array}{r}\text { Redundant Fixed } \\
\text { Effects Tests }\end{array}$ \\
\hline \multicolumn{2}{|c|}{0.943274} & \multicolumn{2}{|c|}{0.743149} & \multicolumn{2}{|c|}{0.858892} & Akaike info criterion \\
\hline \multicolumn{2}{|c|}{1.722941} & \multicolumn{2}{|c|}{1.522816} & \multicolumn{2}{|c|}{1.638559} & Schwarz criterion \\
\hline
\end{tabular}

يلاحظ من الجدول ( 17 ) ، بان الاثار الثابتة للفترات كاتت معنوية في حالة وجود قاطع واتجاه عام

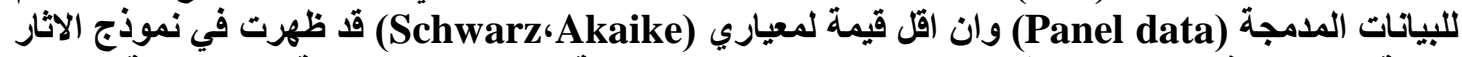

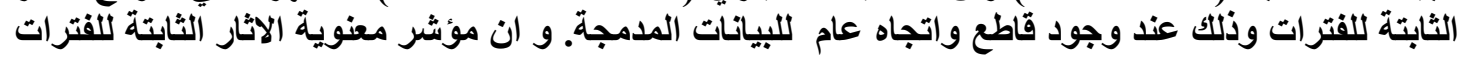

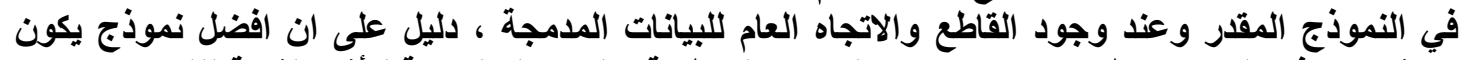

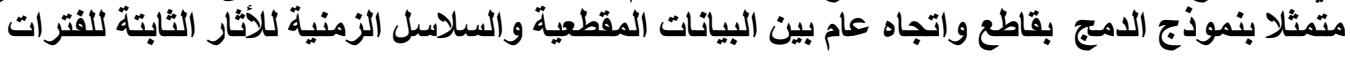




$$
66 \text { العدد }
$$

تاثير استقرارية بـعض الانشطة السلعية في العراق على تقدير نماذف

$$
\text { البيانات المقطعية للفنترة (1988-2000) }
$$

8 :- نتائج الاختبار على مستوى الفروق الاولى للبيانات المقطعية والسلاسل الزمنية للأثار

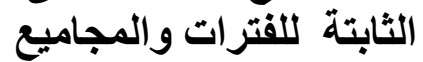

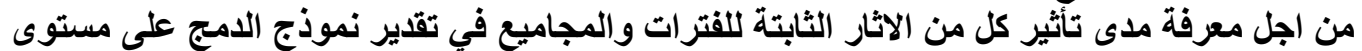

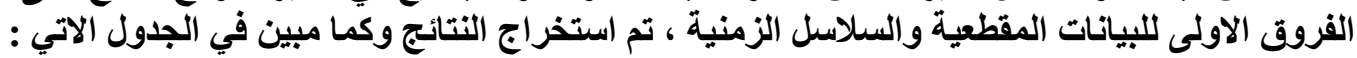

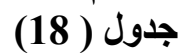

نتائج الاختبار على مستوى الفروق الاولى للبيانات المقطعية والسلاسل الزمنية للأثار الثابتة للفترات

\begin{tabular}{|c|c|c|c|c|c|c|}
\hline \multicolumn{2}{|c|}{ عدم وجود قاطع واتجاه عام } & \multicolumn{2}{|c|}{ بوجود قاطع واتجاه عام } & \multicolumn{2}{|c|}{ بوجود قاطع } & \multirow[t]{2}{*}{ الاختبار } \\
\hline الاحتمالية & $\mathbf{F}$ & الاحتمالية & $\mathbf{F}$ & الاحتمالية & $\mathbf{F}$ & \\
\hline 0.1162 & 1.714758 & $0.0437 *$ & 2.174309 & $* * 0.0084$ & 2.979708 & $\begin{array}{r}\text { Redundant Fixed } \\
\text { Effects Tests }\end{array}$ \\
\hline \multicolumn{2}{|c|}{0.806191} & \multicolumn{2}{|c|}{0.790459} & \multicolumn{2}{|c|}{0.712489} & Akaike info criterion \\
\hline \multicolumn{2}{|c|}{1.702808} & \multicolumn{2}{|c|}{1.687077} & \multicolumn{2}{|c|}{1.609106} & Schwarz criterion \\
\hline
\end{tabular}

والمجاميع

يلاحظ من الجدول (18) ، بان الاثار الثابتة للفترات والمجاميع كانت معنوية في حالة وجود قاطع في

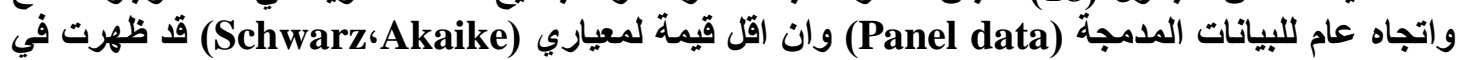

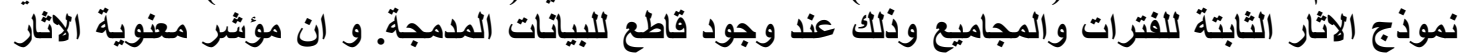

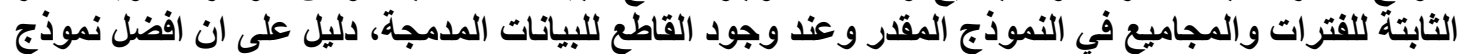

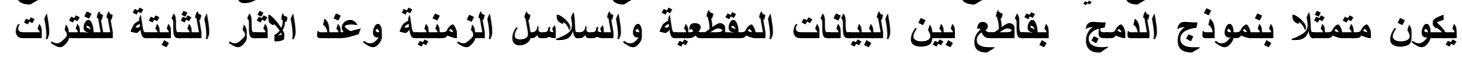

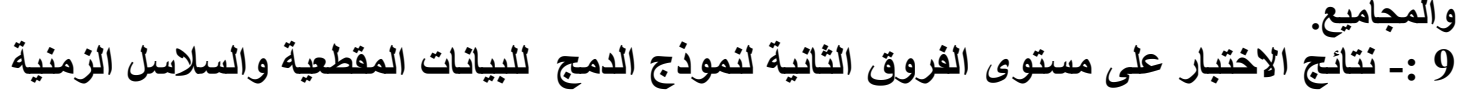
من اجل تقدير نموذج الاميج على مستوى الفروق للبيانات المقطعية والسلاسل الزمنية، تم استخراج النتانية النتائج

جدول (19) (19) وكما مبين في الجدول الاتي :

\begin{tabular}{|c|c|c|c|}
\hline عدم وجود قاطع واتجاه عام & بوجود قاطع واتجاه عام & بوجود قاطع & الاختبار \\
\hline $\mathbf{0 . 8 9 5 9 3 7}$ & $\mathbf{1 . 7 5 8 7 2 9}$ & 1.888721 & Akaike info criterion \\
\hline 1.246788 & 2.138727 & 2.268719 & Schwarz criterion \\
\hline
\end{tabular}

نتائج الاختبار على مستوى الفروق الثانية لنموذج الدمج للبيانات المقطعية والسلاسل الزمنية

يلاحظ من الجدول (19) ، بان اقل قيمة لمعياري (Schwarz،Akaike) قد ظهرت في نموذج الدمبج

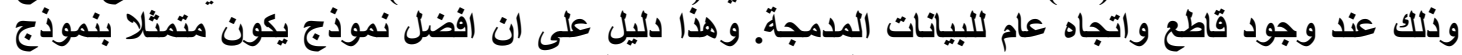
الامج بقاطع واتجاه عام بين البيانات المقطعية والسلاسل والئل الزمنية . 


$$
66 \text { العدد }
$$

تاثير استقرارية بعضر الانشطة السلعية في العراق على تقدير نماذج

$$
\text { البيانات المقطعية للفترة (1988-2000) }
$$

10:- نتائج الاختبار على مستوى الفروق الثانية للبيانات المقطعية والسلاسل الزمنية للأثار

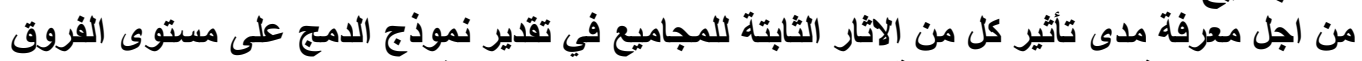

الثابتة للمجاميع

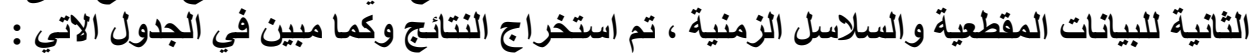

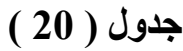

\begin{tabular}{|c|c|c|c|c|c|c|}
\hline \multicolumn{2}{|c|}{ عدم وجود قاطع واتجاه عام } & \multicolumn{2}{|c|}{ بوجود قاطع واتجاه عام } & \multicolumn{2}{|c|}{ بوجود قاطع } & \multirow{2}{*}{ الاختبار } \\
\hline الاحتمالية & $\mathbf{F}$ & الاحتمالية & $\mathbf{F}$ & الاحتمالية & $\mathbf{F}$ & \\
\hline 0.1604 & 1.823215 & 0.9722 & 0.076560 & 0.9949 & 0.023907 & $\begin{array}{r}\text { Redundant Fixed } \\
\text { Effects Tests }\end{array}$ \\
\hline \multicolumn{2}{|c|}{0.879495} & \multicolumn{2}{|c|}{1.760709} & \multicolumn{2}{|c|}{1.893712} & Akaike info criterion \\
\hline \multicolumn{2}{|c|}{1.347295} & \multicolumn{2}{|c|}{2.247306} & \multicolumn{2}{|c|}{2.380309} & Schwarz criterion \\
\hline
\end{tabular}

نتائج الاختبار على مستوى الفروق الثانية للبيانات المقطعية والسلاسل الزمنية للأثار الثابتة للمجاميع

يلاحظ من الجدول (20)، بان الاثار الثابتة للمجاميع كاتت غير معنوية وان اقل قيمة لمعياري

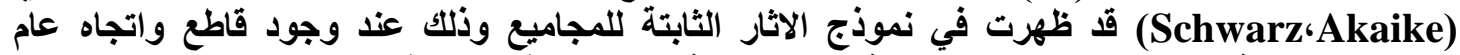

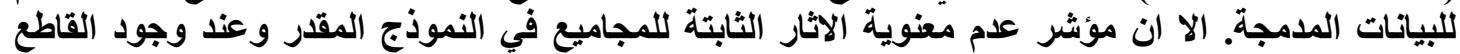

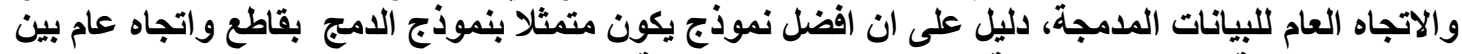

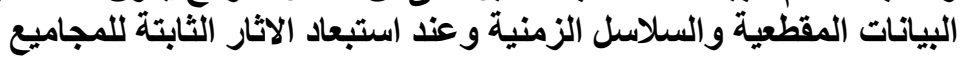

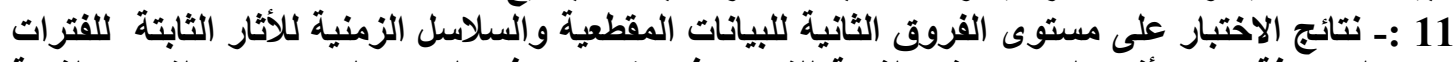

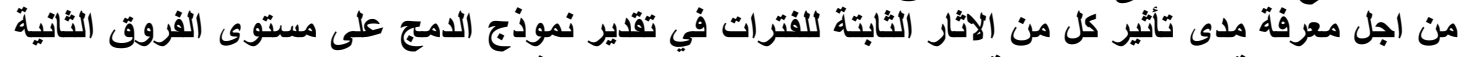

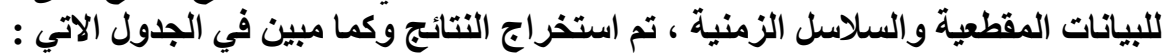

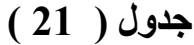

\begin{tabular}{|c|c|c|c|c|c|c|}
\hline \multicolumn{2}{|c|}{ عدم وجود قاطع واتجاه } & \multicolumn{2}{|c|}{ بوجود قاطع واتجاه عام } & \multicolumn{2}{|c|}{ بوجود قاطع } & \multirow[t]{2}{*}{ الاختبار } \\
\hline الاحتمالية & $\mathbf{F}$ & الاحتمالية & $\mathbf{F}$ & الاحتمالية & $\mathbf{F}$ & \\
\hline 0.2784 & 1.293906 & $* * 0.0001$ & 6.051897 & $0.0001 * *$ & 6.675412 & $\begin{array}{r}\text { Redundant Fixed } \\
\text { Effects Tests }\end{array}$ \\
\hline \multicolumn{2}{|c|}{0.943274} & \multicolumn{2}{|c|}{$\mathbf{0 . 8 5 6 1 8 0}$} & \multicolumn{2}{|c|}{0.913896} & $\begin{array}{c}\text { Akaike info } \\
\text { criterion }\end{array}$ \\
\hline \multicolumn{2}{|c|}{1.722941} & \multicolumn{2}{|c|}{1.626625} & \multicolumn{2}{|c|}{1.684342} & Schwarz criterion \\
\hline
\end{tabular}

نتائج الاختبار على مستوى الفروق الثانية للبيانات المقطعية والسلاسل الزمنية للأثار الثابتة للفترات

يلاحظ من الجدول (21 ) ، بان الاثار الثابتة للفترات كاتت معنوية في حالة وجود قاطع واتجاه عام للبيانات

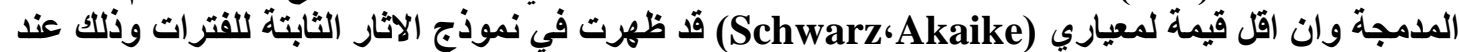

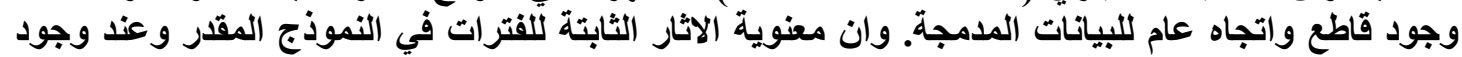

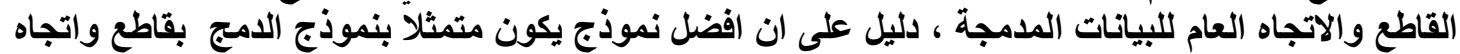

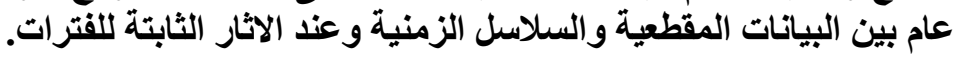




\section{6 العدادئ}

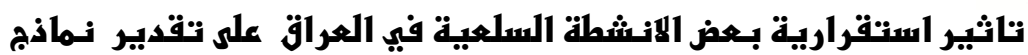

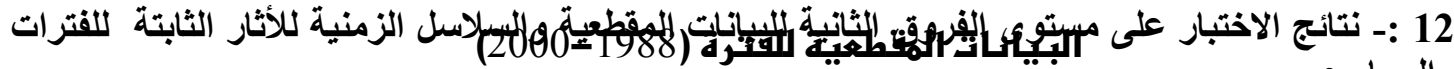
والمجاميع.

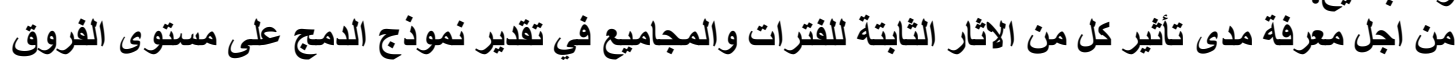

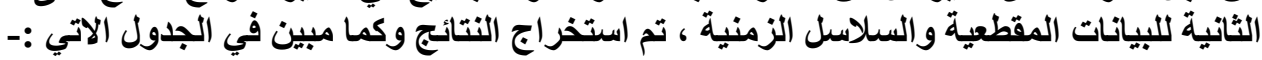
جدول (22)

نتائج الاختبار على مستوى الفروق الثانية للبيانات المقطعية والسلاسل الزمنية للأثار الثابتة للفترات

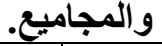

\begin{tabular}{|c|c|c|c|c|c|c|}
\hline \multicolumn{2}{|c|}{ عدم وجود قاطع واتجاه عام } & \multicolumn{2}{|c|}{ بوجود قاطع واتجاه عام } & \multicolumn{2}{|c|}{ بوجود قاطع } & \multirow[t]{2}{*}{ الاختبار } \\
\hline الاحتمالية & $\mathbf{F}$ & الاحتمالية & $\mathbf{F}$ & الاحتمالية & $\mathbf{F}$ & \\
\hline 0.1162 & 1.714758 & $0.0008 * *$ & 4.675707 & $0.0009 * *$ & 4.52935 & $\begin{array}{r}\text { Redundant Fixed } \\
\text { Effects Tests }\end{array}$ \\
\hline \multicolumn{2}{|c|}{0.806191} & \multicolumn{2}{|c|}{0.897211} & \multicolumn{2}{|c|}{1.048553} & Akaike info criterion \\
\hline \multicolumn{2}{|c|}{1.702808} & \multicolumn{2}{|c|}{1.789306} & \multicolumn{2}{|c|}{1.940648} & Schwarz criterion \\
\hline
\end{tabular}

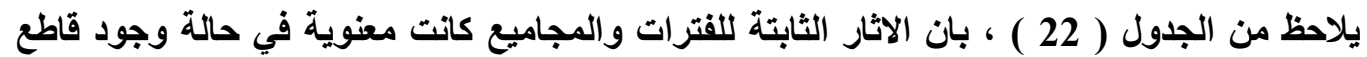

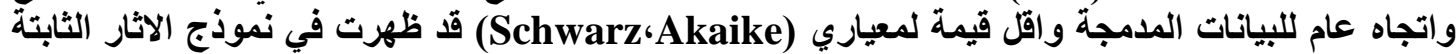

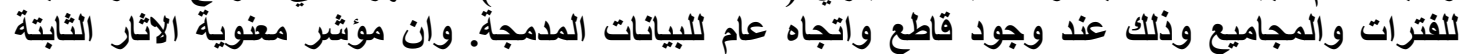

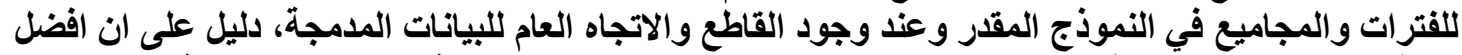

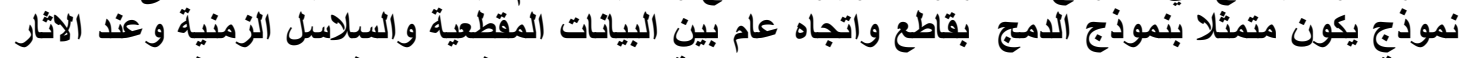

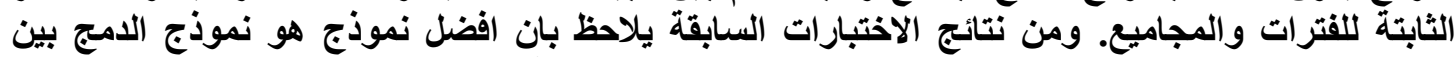

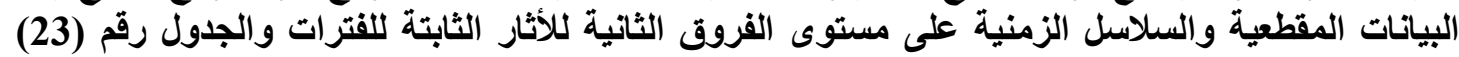
يبين نتائج تقدير هذا النموذج. 


\section{العدد 66}

تاثير استقرارية بعضر الانشطة السلعية في العراق على تقدير نماذج

$$
\text { البيانات المقطعية للفترة (1988-2000) }
$$

جدول ( 23 )

الامج بين البيانات المقطعية والسلاسل الزمنية على مستوى الفروق الثانية للأثار الثابتة للفترات

\begin{tabular}{|c|c|c|c|c|}
\hline للاختبار الاحتمالية & 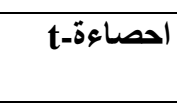 & الخطيأ & قيمة المعامل & 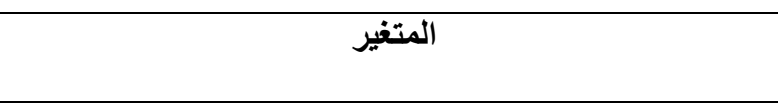 \\
\hline 0.9853 & -0.018664 & 0.036449 & -0.000680 & الحد الثابت \\
\hline 0.8434 & -0.199673 & 1.998304 & -0.399008 & عدد العمال على مستوى الفرق الاول للقطاع الزراعي \\
\hline$* * 0.0052$ & 3.065358 & 0.117531 & 0.360275 & عدد العمال على مستوى الفرق الاول لقطاع الصناعة التحويلية \\
\hline 0.1074 & -1.669798 & 1.054948 & -1.761549 & عدد العمال على مستوى الفرق الاول لقطاع الكهرباء والماء \\
\hline 0.1958 & $\mathbf{1 . 3 2 9 3 0 0}$ & $\mathbf{0 . 3 3 1 2 2 5}$ & 0.440298 & عدد العمال على مستوى الفرق الاول لقطاع البناء والتثشييد \\
\hline$* 0.0395$ & -2.173087 & 0.090482 & -0.196625 & الاستثمار على مستوى الفرق الاول للقطاع الزراعي \\
\hline $\mathbf{0 . 7 3 0 3}$ & -0.348580 & 0.068976 & -0.024044 & الاستثمار على مستوى الفرق الاول لقطاع الصناعة التحويلية \\
\hline 0.5059 & -0.674937 & $\mathbf{0 . 0 7 6 8 9 0}$ & -0.051896 & الاستثمار على مستوى الفرق الاول لقطاع الكهرباء والماء \\
\hline$* 0.0246$ & 2.392260 & $\mathbf{0 . 1 0 8 5 9 7}$ & 0.259793 & الاستثمار على مستوى الفرق الاول لقطاع البناء والتشييا \\
\hline & & & & Fixed Effects (Period) \\
\hline & & & -0.301233 & 1990--C \\
\hline & & & -0.307209 & 1991--C \\
\hline & & & 0.839038 & 1992--C \\
\hline & & & -0.231172 & 1993--C \\
\hline & & & -0.283493 & 1994--C \\
\hline & & & 0.332659 & 1995--C \\
\hline & & & -0.274316 & 1996--C \\
\hline & & & 0.192139 & 1997--C \\
\hline & & & -0.080100 & 1998--C \\
\hline & & & 0.201769 & 1999--C \\
\hline & & & $-\mathbf{0 . 0 8 8 0 8 3}$ & 2000--C \\
\hline 0.004511 & \multicolumn{2}{|c|}{ Mean dependent var } & $\mathbf{0 . 7 8 6 3 7 5}$ & R-squared \\
\hline 0.393135 & \multicolumn{2}{|c|}{ S.D. dependent var } & 0.632566 & Adjusted R-squared \\
\hline 5.112654 & \multicolumn{2}{|c|}{ F-statistic } & 0.238304 & S.E. of regression \\
\hline \multirow[t]{3}{*}{0.000116} & \multicolumn{2}{|c|}{ Prob(F-statistic) } & 1.419719 & Sum squared resid \\
\hline & & & 13.10878 & Log likelihood \\
\hline & & & 2.805401 & Durbin-Watson stat \\
\hline
\end{tabular}




\section{6 العدد 6}

تاثير استقرارية بعضر الانشطة السلعية في العراق على تقدير نماذج

$$
\text { البيانات المقطعية للفنترة (1988-2000) }
$$

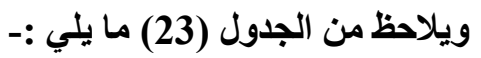

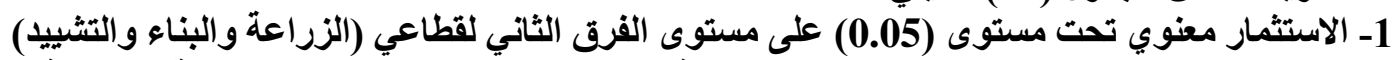

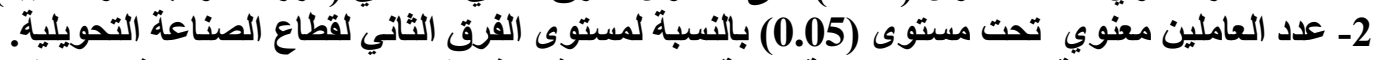

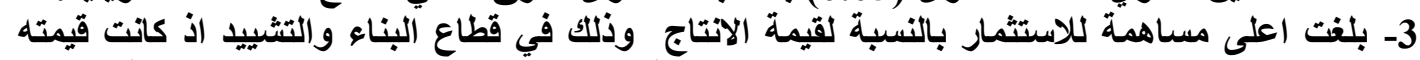

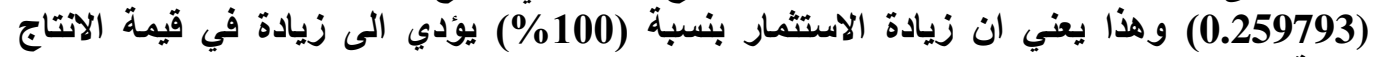

4- بلغت اعلى مساهمة لعدد العمال بالنسبة لقيمة الانتاج وذلك في قطاع الصناعة التحويلية بحيث

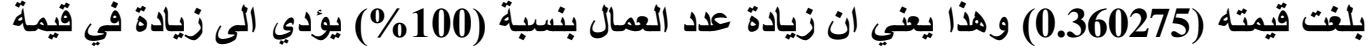

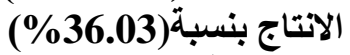

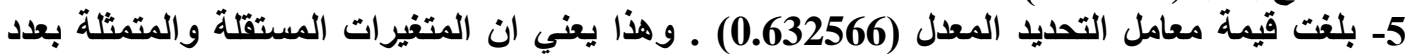

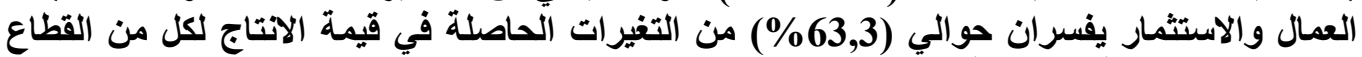

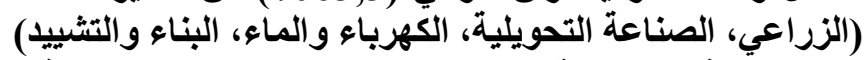

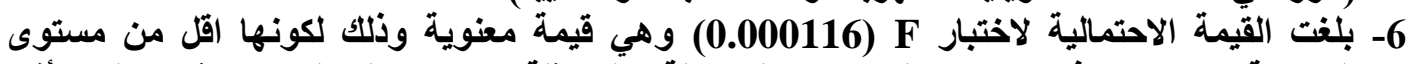

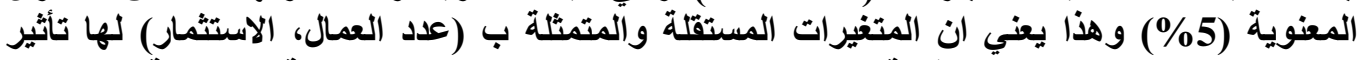

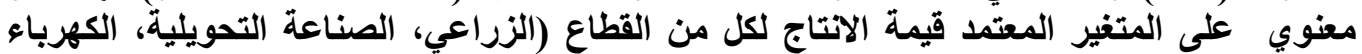

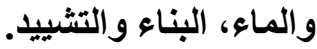




\section{6 العدد 60}

تاثير استقرارية بـعض الانشطة السلعية في العراق على تقدير نماذج

$$
\begin{aligned}
& \text { البيانات المقطعية للفترة (1988-2000) }
\end{aligned}
$$

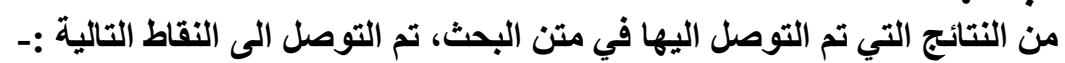

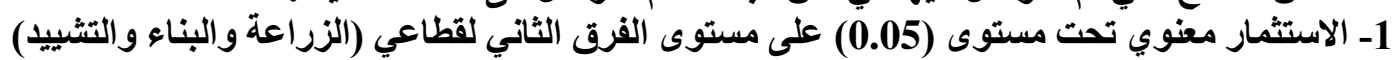

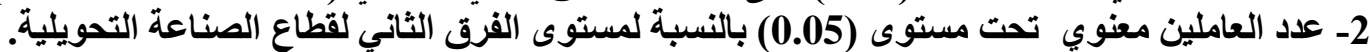

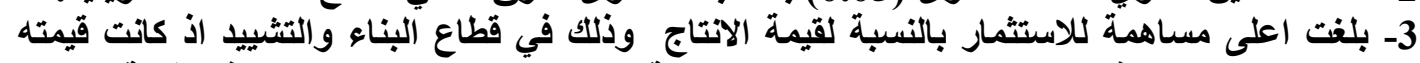

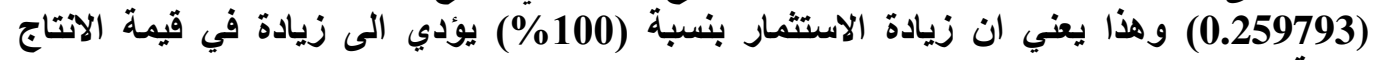

بنسبة) (025.98)

4- بلغت اعلى مساهمة لعدد العمال بالنسبة لقيمة الانتاج وذللك في قطاع الصناعة التحويلية بحيث

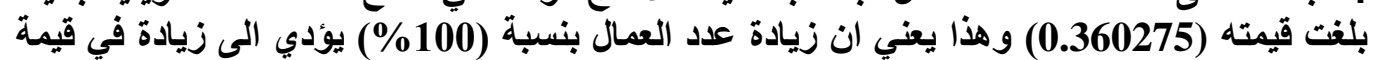

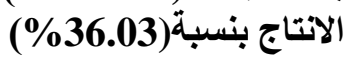

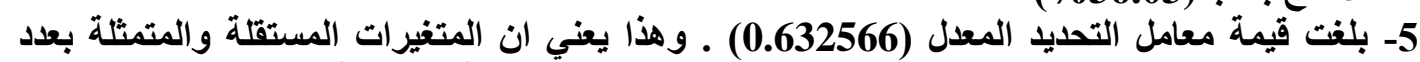

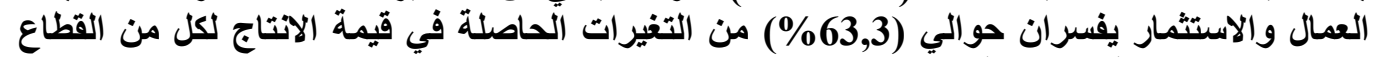

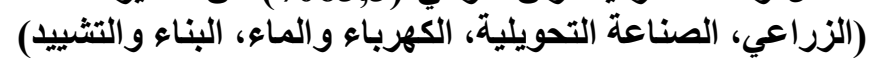

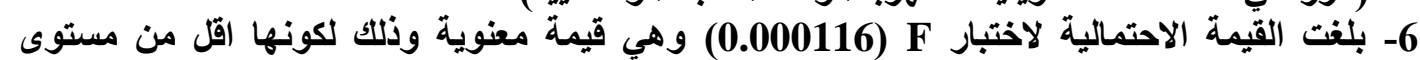

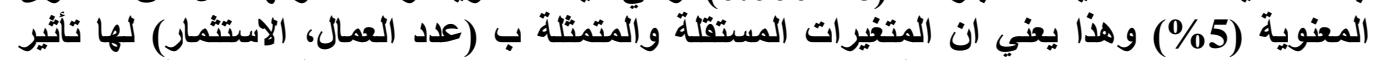

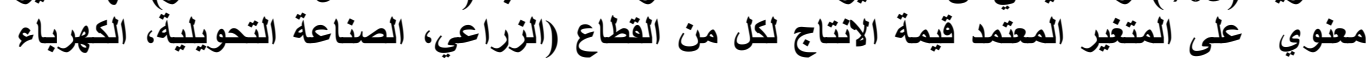
والماء، البناء و التثييد.

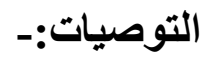

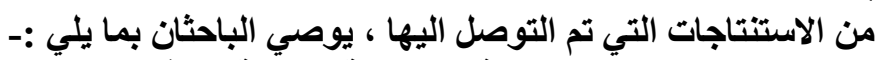

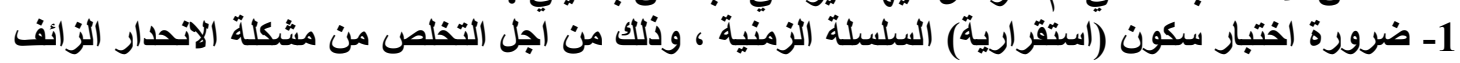
والحصول على افضل النتون النتائج.

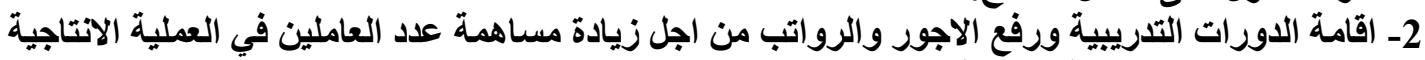

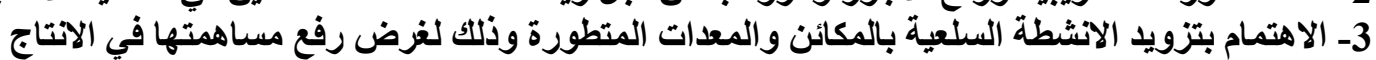

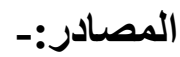

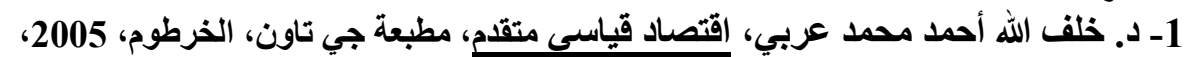

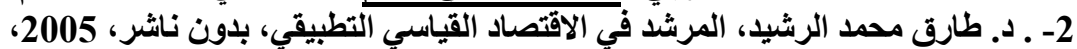

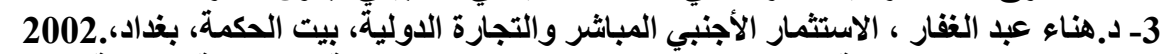

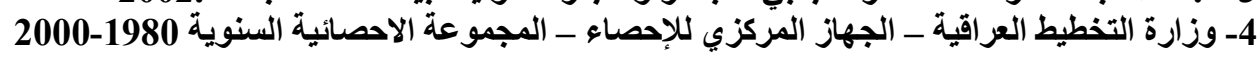

5-Ben "Econometrics ,theory and application with eviews "2005, Printed and bound in MaJaysia

6- Bruce E. Hansen, ECONOMETRICS, WWW.SSC.EDU/BHANSEN, 2001,

Copyright $\odot$ 1994-2005 Quantitative Micro Software, LLC $^{1}{ }^{\text {}}$ 7-Eviews 5.1, Printed in the United States of America

)(Linear Regression Models for Panel Data Using SAS, Stata, 8-Hun Myoung Park (kucc625) (c) 2005-2008 The Trustees of Indiana University (11/15/2008) Linear Regression Models for Panel Data: 1

9- RITCHARD HARRIS, Using COINTEGRATION ANALYSIS IN ECONOMICS MODLELLINMG, Prentice Hall, LONDON, 1995

10-Wooldridge, Jeffrey M. (2002). Econometric Analysis of Cross Section and Panel Data, Cambridge, MA: The MIT Press. 